\title{
Insights into atmospheric oxidation processes by performing factor analyses on subranges of mass spectra
}

\author{
Yanjun Zhang ${ }^{1}$, Otso Peräkylä ${ }^{1}$, Chao Yan ${ }^{1}$, Liine Heikkinen ${ }^{1}$, Mikko Äijälä ${ }^{1}$, Kaspar R. Daellenbach ${ }^{1}$, Qiaozhi Zha ${ }^{1}$, \\ Matthieu Riva $^{1,2}$, Olga Garmash ${ }^{1}$, Heikki Junninen ${ }^{1,3}$, Pentti Paatero ${ }^{1}$, Douglas Worsnop ${ }^{1,4}$, and Mikael Ehn ${ }^{1}$ \\ ${ }^{1}$ Institute for Atmospheric and Earth System Research/Physics, Faculty of Science, \\ University of Helsinki, Helsinki, 00014, Finland \\ ${ }^{2}$ Univ. Lyon, Université Claude Bernard Lyon 1, CNRS, IRCELYON, 69626, Villeurbanne, France \\ ${ }^{3}$ Institute of Physics, University of Tartu, Tartu, 50090, Estonia \\ ${ }^{4}$ Aerodyne Research, Inc., Billerica, MA 01821, USA
}

Correspondence: Yanjun Zhang (yanjun.zhang@helsinki.fi)

Received: 18 September 2019 - Discussion started: 28 November 2019

Revised: 23 March 2020 - Accepted: 26 March 2020 - Published: 19 May 2020

\begin{abstract}
Our understanding of atmospheric oxidation chemistry has improved significantly in recent years, greatly facilitated by developments in mass spectrometry. The generated mass spectra typically contain vast amounts of information on atmospheric sources and processes, but the identification and quantification of these is hampered by the wealth of data to analyze. The implementation of factor analysis techniques have greatly facilitated this analysis, yet many atmospheric processes still remain poorly understood. Here, we present new insights into highly oxygenated products from monoterpene oxidation, measured by chemical ionization mass spectrometry, at a boreal forest site in Finland in autumn 2016. Our primary focus was on the formation of accretion products, i.e., dimers. We identified the formation of daytime dimers, with a diurnal peak at noontime, despite high nitric oxide (NO) concentrations typically expected to inhibit dimer formation. These dimers may play an important role in new particle formation events that are often observed in the forest. In addition, dimers identified as combined products of $\mathrm{NO}_{3}$ and $\mathrm{O}_{3}$ oxidation of monoterpenes were also found to be a large source of low-volatility vapors at night. This highlights the complexity of atmospheric oxidation chemistry and the need for future laboratory studies on multi-oxidant systems. These two processes could not have been separated without the new analysis approach deployed in our study, where we applied binned positive matrix factorization (binPMF) on subranges of the mass spectra rather than the traditional approach where the entire mass spectrum
\end{abstract}

is included for PMF analysis. In addition to the main findings listed above, several other benefits compared to traditional methods were found.

\section{Introduction}

Huge amounts of volatile organic compounds (VOCs) are emitted to the atmosphere every year (Guenther et al., 1995; Lamarque et al., 2010), which play a significant role in atmospheric chemistry and affect the oxidative ability of the atmosphere. The oxidation products of VOCs can contribute to the formation and growth of secondary organic aerosols (Kulmala et al., 2013; Ehn et al., 2014; Kirkby et al., 2016; Troestl et al., 2016), affecting air quality, human health, and climate radiative forcing (Pope et al., 2009; Stocker et al., 2013; Zhang et al., 2016; Shiraiwa et al., 2017). Thanks to the advancement in mass spectrometric applications, like the aerosol mass spectrometer (AMS) (Canagaratna et al., 2007) and chemical ionization mass spectrometry (CIMS) (Bertram et al., 2011; Jokinen et al., 2012; Lee et al., 2014), our capability to detect these oxidized products, as well as our understanding of the complicated atmospheric oxidation pathways in which they take part, has been greatly enhanced.

Monoterpenes $\left(\mathrm{C}_{10} \mathrm{H}_{16}\right)$, one major group of VOCs emitted in forested areas, have been shown to be a large source of atmospheric secondary organic aerosol (SOA). The oxidation of monoterpenes produces an abundance of differ- 
ent oxidation products (oxygenated VOC, OVOC), including highly oxygenated organic molecules (HOMs) with molar yields in the range of a few percent, depending on the specific monoterpene and oxidant (Ehn et al., 2014; Bianchi et al., 2019). Recent chamber studies have greatly advanced our knowledge of formation pathways for monoterpene HOM products, e.g., monomers (typically $\mathrm{C}_{9-10} \mathrm{H}_{12-16} \mathrm{O}_{6-12}$ ) and dimers (typically $\mathrm{C}_{19-20} \mathrm{H}_{28}-32 \mathrm{O}_{8-18}$ ). Dimers, as shown by previous studies, can contribute to new particle formation (NPF) (Kirkby et al., 2016; Troestl et al., 2016; Lehtipalo et al., 2018), and they are thus of particular interest.

In nearly all atmospheric oxidation chemistry, peroxy radicals $\left(\mathrm{RO}_{2}\right)$ are the key intermediates (Orlando and Tyndall, 2012). They form when VOCs react with oxidants like ozone, or the hydroxyl $(\mathrm{OH})$ or nitrate $\left(\mathrm{NO}_{3}\right)$ radicals, while their termination occurs mainly by bimolecular reactions with nitric oxide (NO), hydroperoxyl $\left(\mathrm{HO}_{2}\right)$, and/or other $\mathrm{RO}_{2}$. $\mathrm{RO}_{2}+\mathrm{R}^{\prime} \mathrm{O}_{2}$ reactions can form ROOR' dimers (Berndt et al., 2018a, b), and this pathway competes with $\mathrm{RO}_{2}+\mathrm{NO}$ reactions, meaning that $\mathrm{NO}$, formed by photolysis of $\mathrm{NO}_{2}$, can efficiently suppress dimer formation, as also seen from atmospheric HOM observations (Ehn et al., 2014; Yan et al., 2016). Mohr et al. (2017) also reported daytime dimers in the boreal forest in Finland, coinciding with NPF events. A better understanding of the formation of these daytime dimers would assist elucidating NPF and particle growth mechanisms.

At night, nitrogen oxides can also impact the oxidation pathways when $\mathrm{NO}_{2}$ and $\mathrm{O}_{3}$ react to form $\mathrm{NO}_{3}$ radicals that can oxidize monoterpenes. $\mathrm{NO}_{3}$ radicals are greatly reduced during daytime due to photolysis and reactions with NO reducing their lifetime to a few seconds ( $\mathrm{Ng}$ et al., 2017). Yan et al. (2016) reported nighttime $\mathrm{HOMs}$ initiated by $\mathrm{NO}_{3}$ in the boreal forest in Finland, but to our knowledge there have been no laboratory studies on $\mathrm{HOM}$ formation from $\mathrm{NO}_{3}$ oxidation of monoterpenes. However, there have been several studies looking into the SOA formation in these systems, finding that certain monoterpenes, like $\beta$-pinene, have very high SOA yields, while the most abundant monoterpene, $\alpha$ pinene, has negligible SOA forming potential. It remains an open question as to what the role of $\mathrm{NO}_{3}$ radical oxidation of monoterpenes, and the observed $\mathrm{NO}_{3}$-derived $\mathrm{HOMs}$, in the nighttime boreal forest is. Identification of these processes in the ambient environment is fundamental for better understanding of NPF and SOA.

The recent development of CIMS techniques has allowed researchers to observe unprecedented numbers of OVOCs in real time (Riva et al., 2019). This ability to measure thousands of compounds is a great benefit, but it is also a large challenge for the data analyst. For this reason, factor analytical techniques have often been applied to reduce the complexity of the data (Huang et al., 1999), e.g., positive matrix factorization, PMF (Paatero and Tapper, 1994; Zhang et al., 2011). The factors have then been attributed to sources (e.g., biomass burning organic aerosol) or processes (e.g., monoterpene ozonolysis) depending on the application and ability to identify spectral signatures (Yan et al., 2016; Zhang et al., 2017).

In the vast majority of these PMF applications to mass spectra, the mass range of ions has been maximized in order to provide as much input as possible for the algorithm. This approach was certainly motivated in the early application of PMF by, for example, offline filters, with chemical information of metals, water-soluble ions, and organic carbon and elemental carbon (OC and EC), where the number of variables is counted in tens, and the number of samples in tens or hundreds (Zhang et al., 2017). However, with gas-phase CIMS, we often have up to a thousand variables, with hundreds or even thousands of samples, meaning that the amount of data itself is unlikely to be a limitation for PMF calculation. In this work, we aimed to explore potential benefits of dividing the spectra into subranges before applying factorization analysis. This approach was motivated by several issues, which we expected to be resolvable by analyzing several mass ranges separately. Firstly, the loss rate of OVOCs by condensation is strongly coupled to the molecular mass (Peräkylä et al., 2020), likely giving very different behaviors for the high and low mass ranges, even when produced by the same source. Second, dimers are a product of two $\mathrm{RO}_{2}$ radicals, which can have different sources, meaning that they may have temporal profiles unlike anything observable for monomers. Finally, if one mass range contains much less signal than another, it will have very little impact on the final PMF results.

In this study, we applied PMF analysis on three different mass ranges of mass spectra of OVOCs measured by a chemical ionization atmospheric pressure interface time-offlight (CI-APi-TOF; Jokinen et al., 2012) mass spectrometer in the Finnish boreal forest. We utilized our recently proposed new PMF approach, binPMF, to include as much of the high-resolution information in the mass spectra as possible in a robust way (Zhang et al., 2019). We show the benefits of the subrange PMF approach to better separate chemical sources by reducing disturbance from variable loss terms of the OVOCs. Much of the analysis focuses on dimer formation pathways and the role of different nitrogen oxides in these pathways. We find that both daytime dimers and dimers resulting from the combination of different oxidants can be separated with the subrange approach but not with the PMF applied to the full mass range. We believe that this study will provide new perspectives for future studies analyzing gasphase CIMS data.

\section{Methodology}

The focus of this work is on retrieving new information from mass spectra by applying new analytical approaches. Therefore, we chose a dataset that has been presented earlier, though without PMF analysis, by Zha et al. (2018) and was also used in the first study describing the binPMF method 
(Zhang et al., 2019). The measurements are described in more details below in Sect. 2.1, while the data analysis techniques used in this work are presented in Sect. 2.2.

\subsection{Measurements}

\subsubsection{Ambient site}

The ambient measurements were conducted at the Station for Measuring Ecosystem-Atmosphere Relations (SMEAR) II in Finland (Hari and Kulmala, 2005) as part of the Influence of Biosphere-Atmosphere Interactions on the Reactive Nitrogen budget (IBAIRN) campaign (Zha et al., 2018). Located in the boreal environment in Hyytiälä, SMEAR II is surrounded by coniferous forest and has limited anthropogenic emission sources nearby. Diverse measurements of meteorology, aerosol, and gas-phase properties are continuously conducted at the station. Details about the meteorological conditions and temporal variations of trace gases during the IBAIRN campaign are presented by Zha et al. (2018) and Liebmann et al. (2018).

\subsubsection{Instrument and data}

Data were collected with a nitrate $\left(\mathrm{NO}_{3}^{-}\right)$-based chemical ionization atmospheric pressure interface time-of-flight mass spectrometer (CI-APi-TOF, Jokinen et al., 2012) with about $4000 \mathrm{Th} \mathrm{Th}^{-1}$ mass-resolving power at ground level in September 2016. In our study, the mass spectra were averaged to $1 \mathrm{~h}$ time resolution from 6 to 22 September for further analysis. We use the thomson (Th) as the unit for massto-charge ratio, with $1 \mathrm{Th}=1 \mathrm{Da} / \mathrm{e}$, where e is the elementary charge. As all the data discussed in this work are based on negative ion mass spectrometry, we will use the absolute value of the mass-to-charge ratio, although the charge of each ion will be negative. The masses discussed in this work include the contribution from the nitrate ion, 62, unless specifically mentioned. Furthermore, as the technique is based on soft ionization with $\mathrm{NO}_{3}^{-}$ions, any multiple charging effects are unlikely, and therefore the reported mass-to-charge values in thomson can be considered equivalent to the mass of the ion in dalton $(\mathrm{Da})$.

The forest site of Hyytiälä is dominated by monoterpene emissions (Hakola et al., 2006). The main feature of previous CI-APi-TOF measurements in Hyytiälä (Ehn et al., 2014; Yan et al., 2016) has been a bimodal distribution of HOMs, termed monomers and dimers, as they are formed of either one or two $\mathrm{RO}_{2}$ radicals, respectively. For the analysis in this study, we chose three mass-to-charge $(\mathrm{m} / \mathrm{z})$ ranges of $50 \mathrm{Th}$ each (Fig. 1), corresponding to regions between which we expect differences in formation or loss mechanisms. In addition to regions with HOM monomers and HOM dimers, one range was chosen at lower masses, in a region presumably mainly consisting of molecules that are less likely to condense onto aerosol particles (Peräkylä et al., 2020).

\subsection{Positive matrix factorization (PMF)}

After the model of PMF was developed (Paatero and Tapper, 1994), numerous applications have been conducted with different types of environmental data (Song et al., 2007; Ulbrich et al., 2009; Yan et al., 2016; Zhang et al., 2017). By reducing the dimensionality of the measured dataset, the PMF model greatly simplifies the data analysis process with no requirement for prior knowledge of sources or pathways as essential input. The main factors can be further interpreted with their unique or dominant markers (elements or masses).

The basic assumption for PMF modeling is mass balance, which assumes that ambient concentration of a chemical component is the sum of contributions from several sources or processes, as shown in Eq. (1).

$\mathbf{X}=\mathbf{T S} \times \mathbf{M S}+\mathbf{R}$

In Eq. (1), $\mathbf{X}$ stands for the time series of measured concentration of different variables ( $m / z$ in our case), TS represents the temporal variation of factor contributions, MS stands for factor profiles (mass spectral profiles), and $\mathbf{R}$ is the residual as the difference of the modeled and the observed data. The matrices TS and MS are iteratively calculated by a leastsquares algorithm utilizing uncertainty estimates to pursue a minimized $Q$ value as shown in Eq. (2), where $S_{i j}$ is the estimated uncertainty, an essential input in the PMF model.

$Q=\sum \sum\left(\frac{R_{i j}}{S_{i j}}\right)^{2}$

The PMF model was conducted by multilinear engine (ME2) (Paatero, 1999) and interfaced with Source Finder ( $\mathrm{SoFi}$, v6.3) (Canonaco et al., 2013). Signal-to-noise ratio (SNR) was calculated as $\operatorname{SNR}_{i j}=$ abs $\left(X_{i j}\right) /$ abs $\left(S_{i j}\right)$. When the signal-to-noise ratio (SNR) is below 1, the signal of $X_{i j}$ will be down-weighted by replacing the corresponding uncertainty $S_{i j}$ by $S_{i j} / \mathrm{SNR}_{i j}$ (Visser et al., 2015). Future studies should pay attention to the potential risk when utilizing this method since down-weighting low signals element-wise will create a positive bias in the data. Robust mode was chosen in the PMF modeling, where outliers $\left(\left|\frac{R_{i j}}{S_{i j}}\right|>4\right)$ were significantly down-weighted (Paatero, 1997).

\section{3 binPMF}

As a newly developed application of PMF for mass spectral data, binPMF has no requirement for chemical composition information while still taking advantage of the highresolution (HR) mass spectra, saving effort and time (Zhang et al., 2019). To explore the benefits of analyzing separated mass ranges, we applied binPMF to the three separated ranges. The three ranges were also later combined for binPMF analysis as a comparison with the previous results. The PMF model requires both data matrix and error matrix as input, and details of the preparation of data and error matrices are described below. 


\subsubsection{Data matrix}

Unlike normal unit mass resolution (UMR) or HR peak fitting, in binPMF, the mass spectra are divided into small bins after baseline subtraction and mass axis calibration. Linear interpolation was first conducted on the mass spectra with a mass interval of $0.001 \mathrm{Th}$. Then the interpolated data were averaged into bins of $0.02 \mathrm{Th}$ width. We selected three ranges for further analysis based on earlier studies (Ehn et al., 2014; Yan et al., 2016; Bianchi et al., 2019; Peräkylä et al., 2020).

- Range $1, m / z$ 250-300 Th, 51 unit masses $\times 25$ bins per unit mass $=1275$ bins/variables, consisting mainly of molecules with five to nine carbon atoms and four to nine oxygen atoms in our dataset.

- Range $2, m / z 300-350 \mathrm{Th}, 51 \times 25=1275$ bins, mainly corresponding to HOM monomer products, with 9 to 10 $\mathrm{C}$ atoms and 7 to $10 \mathrm{O}$ atoms.

- Range $3, m / z 510-560$ Th, $51 \times 30=1530$ bins, mainly corresponding to HOM dimer products, with carbon numbers of 16 to 20 and 11 to $15 \mathrm{O}$ atoms.

To avoid unnecessary computation, only signal regions with meaningful signals in the mass spectra were binned (Zhang et al., 2019). For a nominal mass $N$, the signal region included in further analyses was between $N-0.2$ and $N+0.3$ Th for Range 1 and Range 2 and between $N-0.2$ and $N+0.4 \mathrm{Th}$ for Range 3. The wider signal regions in Range 3 are due to wider peaks at higher masses. The data were averaged into $1 \mathrm{~h}$ time resolution, and in total we had 384 time points in the data matrix.

\subsubsection{Error matrix}

The error matrix represents the estimated uncertainty for each element of the data matrix, and it is crucial for iterative calculation of the $Q$ minimum. Equation (3) is used for error estimation (Polissar et al., 1998),

$S_{i j}=\sigma_{i j}+\sigma_{\text {noise }}$,

where $S_{i j}$ represents the uncertainty of $m / z j$ at time $i$ and $\sigma_{i j}$ stands for counting statistics uncertainty and is estimated as follows:

$\sigma_{i j}=a \times \frac{\sqrt{I_{i j}}}{\sqrt{t_{\mathrm{s}}}}$,

where $I$ is the signal intensity term, in unit of counts per second (cps); $t_{\mathrm{s}}$ stands for length of averaging in seconds, and $a$ is an empirical coefficient to compensate for unaccounted uncertainties (Allan et al., 2003; Yan et al., 2016) and is 1.28 in our study as previously estimated from laboratory experiments (Yan et al., 2016). The $\sigma_{\text {noise }}$ term was estimated as the median of the standard deviations from signals in the bins in the region between nominal masses, where no physically meaningful signals are expected.

\section{Results}

\subsection{General overview of the dataset and spectrum}

During the campaign, in autumn 2016, the weather was overall sunny and humid with average temperature of $10.8^{\circ} \mathrm{C}$ and relative humidity (RH) of $87 \%$ (Zha et al., 2019). The average concentrations of $\mathrm{NO}_{x}$ and $\mathrm{O}_{3}$ were 0.4 and $21 \mathrm{ppbv}$, respectively. The average total HOM concentration was $\sim$ $10^{8}$ molecules $\mathrm{cm}^{-3}$.

Figure 1 shows the $1 \mathrm{~h}$ averaged mass spectrum taken at 18:00 LT (all times in this paper are in Finnish local time (UTC+2) unless stated otherwise) on 12 September, as an example of the analyzed dataset. In addition to exploring the benefits of this type of subrange analysis in relation to different formation or loss pathways, separating into subranges may also aid factor identification for low-signal regions. As shown in Fig. 1, there is a difference of 1-2 orders of magnitude in the signal intensity between Range 3 and Range $1-$ Range 2. If all ranges are run together, we would expect that the higher signals from Range 1 and Range 2 will drive the factorization. While if run separately, separating formation pathways of dimers in Range 3 will likely be easier. As dimers have been shown to be crucial for the formation of new aerosol particles from monoterpene oxidation (Kirkby et al., 2016; Troestl et al., 2016; Lehtipalo et al., 2018), this information may even be the most critical in some cases, despite the low contribution of these peaks to the total measured signal.

binPMF was separately applied to Range 1, Range 2, Range 3, and a "Range combined" which comprised all three subranges. All the PMF runs for the four ranges were conducted from 2 to 10 factors and repeated 3 times for each factor number, to assure the consistency of the results. Factorization results and evolution with increasing factor number are briefly described in the following sections, separately for each range (Sect. 3.2-3.5). It is worth noting that the factor order in factor evolution does not necessarily correspond to that of the final results. The factor orders displayed in Figs. 2-5 have been modified for further comparison between different ranges. More detailed discussion and comparisons between the results are presented in Sect. 4 .

\section{2 binPMF on Range $1(250-300 \mathrm{Th})$}

As has become routine (Zhang et al., 2011; Craven et al., 2012), we first examined the mathematical parameters of our solutions. From 2 to 10 factors, $Q / Q_{\text {exp }}$ decreased from 2.8 to 0.7 (Fig. S1 in Supplement), and after three factors the decreasing trend was gradually slowing down and approaching 1 , which is the ideal value for $Q / Q_{\exp }$ as a diagnostic parameter. The unexplained variation showed a decline from $18 \%$ to $8 \%$ from 2 to 10 factors.

In the two-factor results, two daytime factors were separated, with peak time both at 14:00-15:00. One factor was 


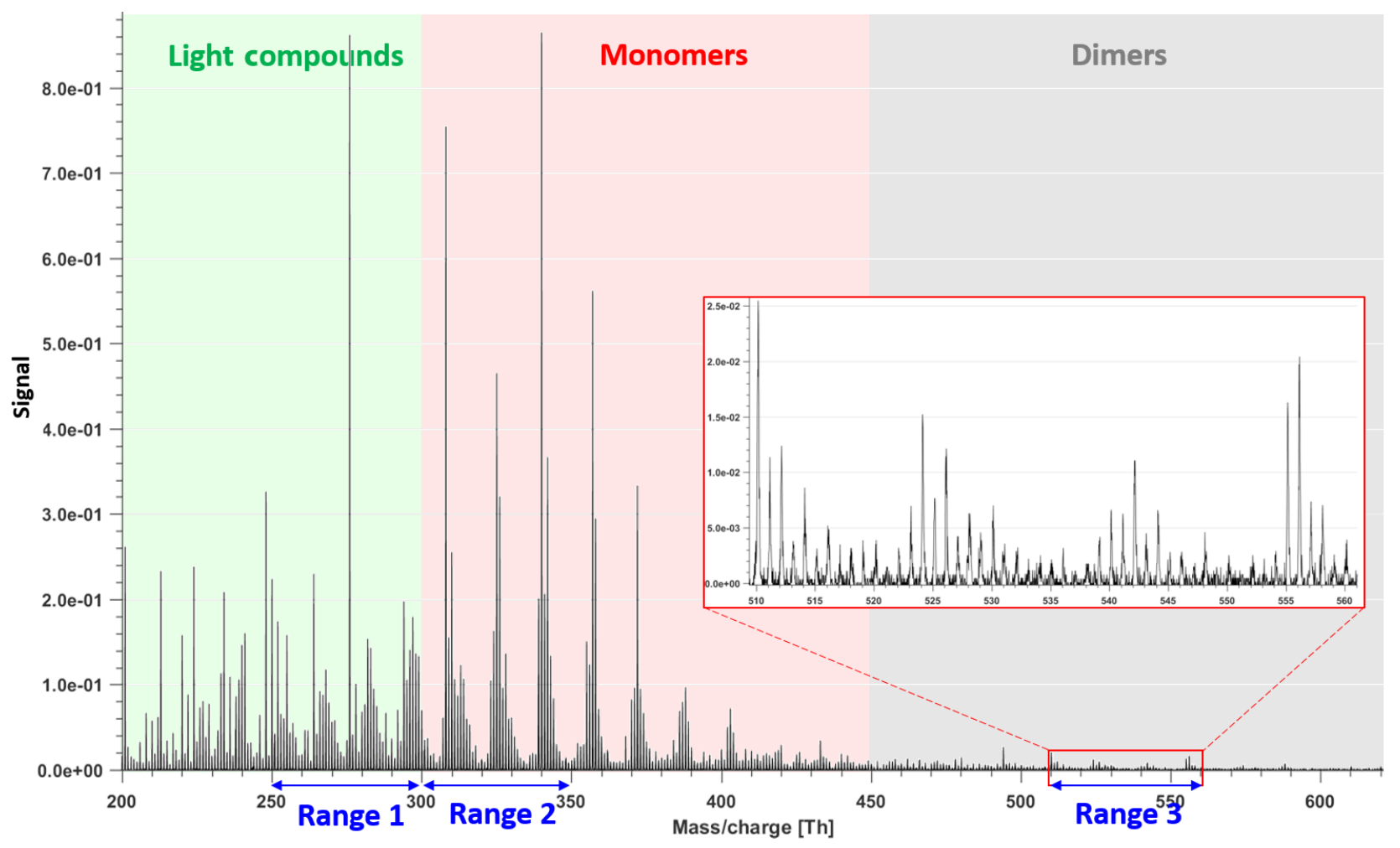

Figure 1. Example of mass spectrum with $1 \mathrm{~h}$ time resolution measured from a boreal forest environment during the IBAIRN campaign (at 18:00 LT, Finnish local time, UTC+2). The mass spectrum was divided into three parts, and three subranges were chosen from different parts for further analysis in our study. The nitrate ion $(62 \mathrm{Th})$ is included in the mass.

characterized by large signals at $m / z 250,255,264,281$, 283, 295, and $297 \mathrm{Th}$. The other factor was characterized by large signals at $m / z 294,250,252,264,266,268$, and 297 Th. In Hyytiälä, as reported in previous studies, odd masses observed by the nitrate CI-APi-TOF are generally linked to monoterpene-derived organonitrates during the day (Ehn et al., 2014; Yan et al., 2016). When the factor number increased to three, the two earlier daytime factors remained similar to the previous result, while a new factor appeared with a distinct sawtooth shape in the diurnal cycle. The main marker in the spectral profile was $m / z 276 \mathrm{Th}$, with a clear negative mass defect. When one more factor was added, the previous three factors remained similar as in the three-factor solution, and a new morning factor was resolved, with $m / z 264$ and 297 Th dominant in the mass spectral profile and a diurnal peak at 11:00.

As the factor number was increased, more daytime factors were separated, with similar spectral profiles to existing daytime factors and various peak times. No nighttime factors were found in the analysis even when the factor number reached 10 . We chose the four-factor result for further discussion, and Fig. 2 shows the result of Range 1, with spectral profile, time series, diurnal cycle, and averaged factor contribution during the campaign. As shown in Fig. 2d, factors 13 are all daytime factors, while factor 4 has no clear diurnal cycle but a distinct sawtooth shape. Factor 4 comes from a contamination of perfluorinated acids from the inlet's automated zeroing every $3 \mathrm{~h}$ during the measurements (Zhang et al., 2019). The zeroing periods have been removed from the dataset before binPMF analysis, but the contamination factor was still resolved. This factor is discussed in more detail in Sect. 4.1 and 4.4.

\section{3 binPMF on Range $2(300-350 \mathrm{Th})$}

This range covers the monoterpene HOM monomer range, and binPMF results have already been discussed by Zhang et al. (2019) as a first example of the application of binPMF on ambient data. Our input data here are slightly different. In the previous study, the $10 \mathrm{~min}$ automatic zeroing every $3 \mathrm{~h}$ was not removed before averaging to $1 \mathrm{~h}$ time resolution, while here we have removed these data. Overall, the results are similar as in our earlier study, and therefore the results are just briefly summarized below for further comparison and discussion in Sect. 4. Similar to Range 1, both the $Q / Q_{\exp }$ (2.2 to $0.6)$ and unexplained variation (16\% to $8 \%$ ) declined with the increased factor number from 2 to 10 .

When the factor number was two, one daytime factor and one nighttime factor were separated, with diurnal peak times at 14:00 and 17:00, respectively. The nighttime factor was characterized by masses at 340,308 , and $325 \mathrm{Th}$ (HOM 


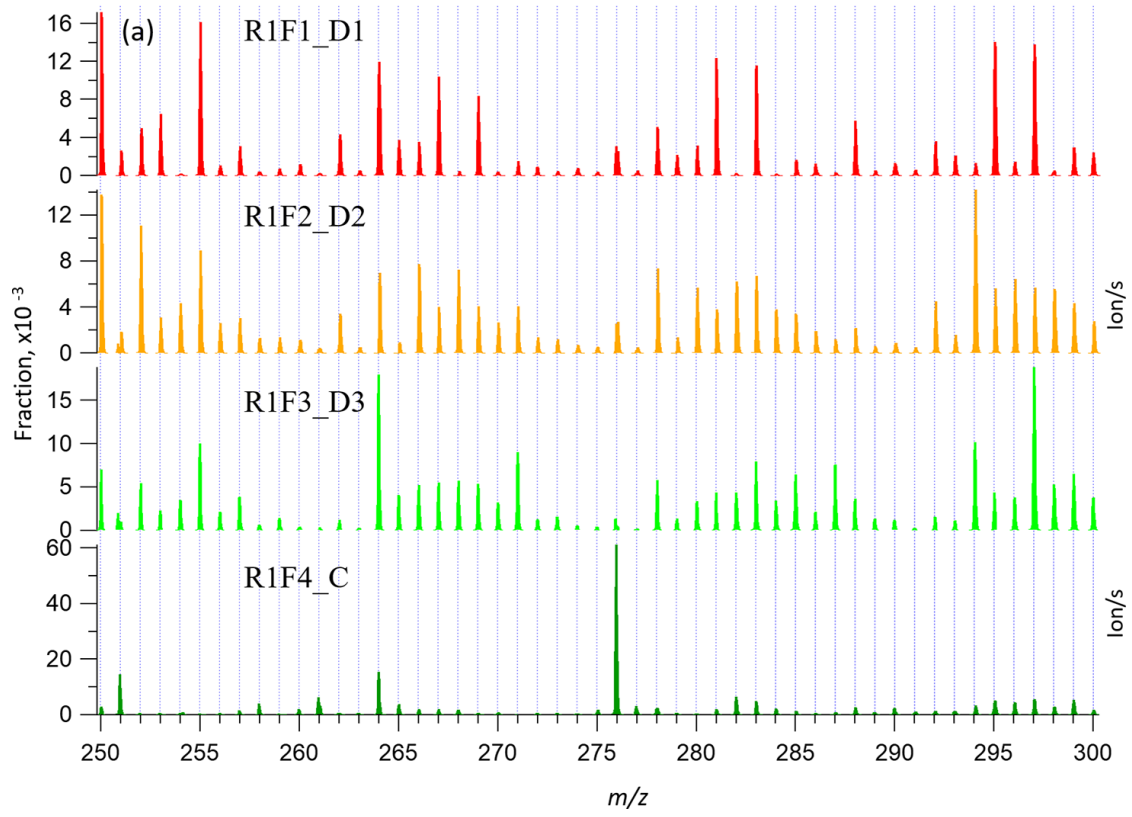

(b)
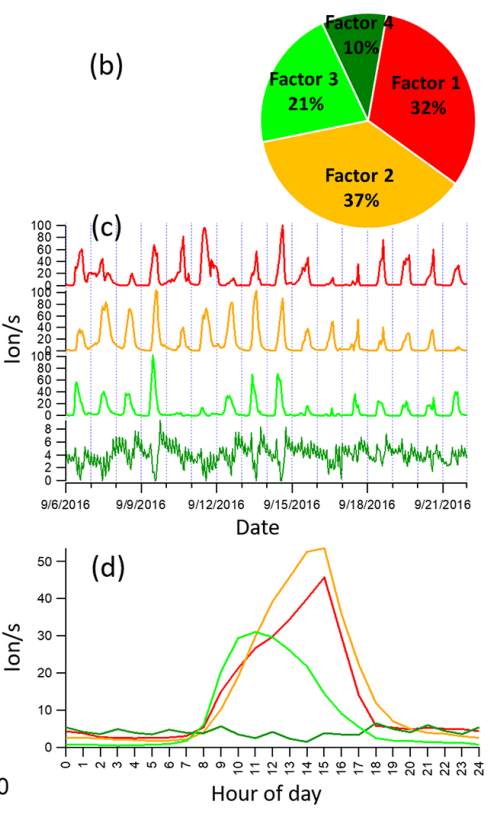

Figure 2. Four-factor result for Range 1 for (a) factor spectral profiles, (b) averaged factor contribution during the campaign, (c) time series, and (d) diurnal trend. Details on the naming schemes for the factors are shown in Table 1.

monomers from monoterpene ozonolysis; Ehn et al., 2014) and remained stable throughout the factor evolution from 2 to 10 factors. With the addition of more factors, no more nighttime factors got separated, while the daytime factor was further separated and more daytime factors appeared, peaking at various times in the morning (10:00), at noon, or in the early afternoon (around 14:00 and 15:00). High contribution of $m / z 339 \mathrm{Th}$ can be found in all the daytime factor profiles. As the factor number reached six, a contamination factor appeared, characterized by large signals at $m / z 339$ and $324 \mathrm{Th}$, showing negative mass defects (Fig. S2). The factor profile is nearly identical to the contamination factor determined in Zhang et al. (2019), where the zeroing periods were not removed, causing larger signals for the contaminants. In our dataset, where the zeroing periods were removed, no sawtooth pattern was discernible in the diurnal trend, yet it could still be separated even though it only contributed 3\% to Range 2. More about the contamination factors from different ranges will be discussed in Sect. 4.4. We chose to show the four-factor result below, to simplify the later discussion and comparison. Figure 3 shows four-factor result of Range 2, with spectral profile, time series, diurnal cycle, and averaged factor contribution during the campaign.

\section{4 binPMF on Range $3(510-560 \mathrm{Th})$}

Range 3 represents mainly the monoterpene HOM dimers (Ehn et al., 2014). Similar to Range 1 and Range 2, both the $Q / Q_{\exp }(1.5$ to 0.6$)$ and unexplained variation $(18 \%$ to $15 \%)$ showed decreasing trend with the increased factor number (2-10). As can be seen from Fig. 1, data in Range 3 had much lower signals compared to those of Range 1 and Range 2, explaining the higher unexplained variation for Range 3.

In the two-factor result for Range 3, one daytime factor and one nighttime factor appeared, with diurnal peak times at noon and 18:00, respectively. The nighttime factor was characterized by ions at $m / z 510,524,526,542,555$, and $556 \mathrm{Th}$, while the daytime factor showed no dominant marker masses, yet with relatively high signals at $m / z 516,518$, and $520 \mathrm{Th}$. As the number of factors increased to three, one factor with almost flat diurnal trend was separated, with dominant masses of 510, 529, and 558 Th. Most peaks in this factor had negative mass defects, and this factor was again linked to a contamination factor. The four-factor result resolved another nighttime factor with a dominant peak at $m / z 555$ Th and effectively zero contribution during daytime. As the factor number was further increased, the new factors seemed like splits from previous factors with similar spectral profiles. We therefore chose the four-factor result also for Range 3 (results shown in Fig. 4) for further discussion.

\section{5 binPMF on Range combined (250-350 and 510-560 Th)}

As a comparison to the previous three ranges, we conducted the binPMF analysis on Range combined, which is the combination of the three ranges. The results of this range are fairly similar to those of Range 1 and Range 2, as could 


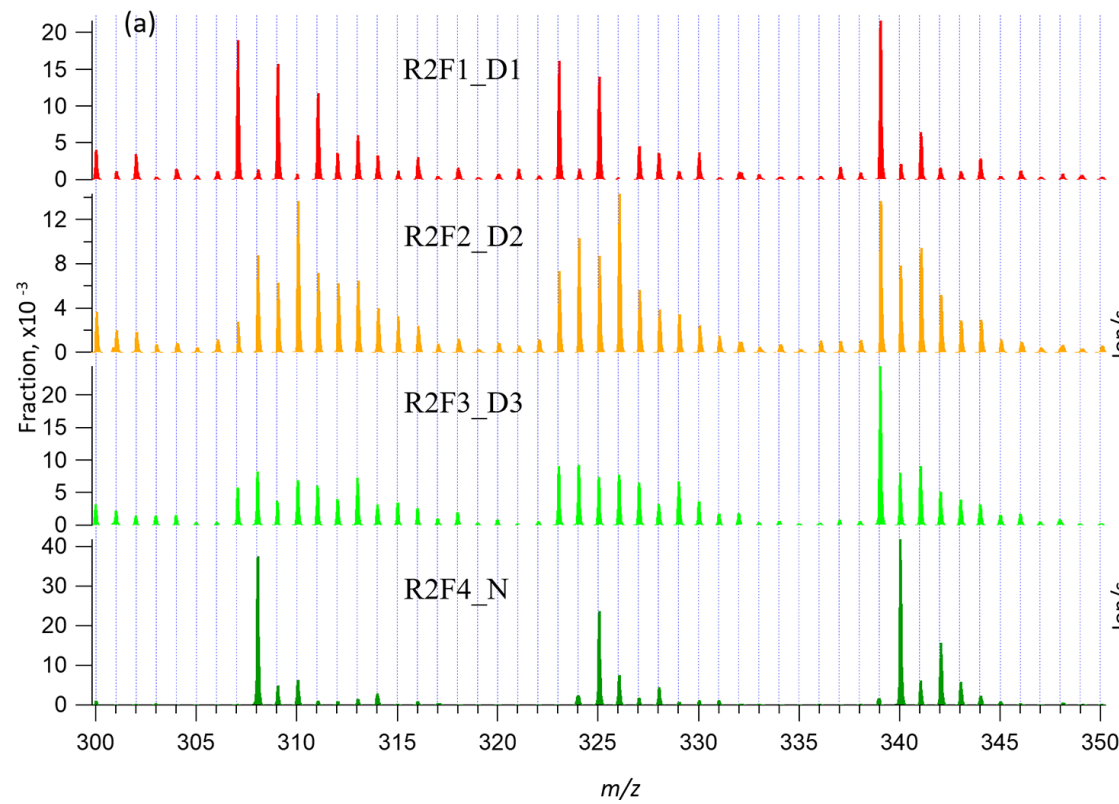

(b)
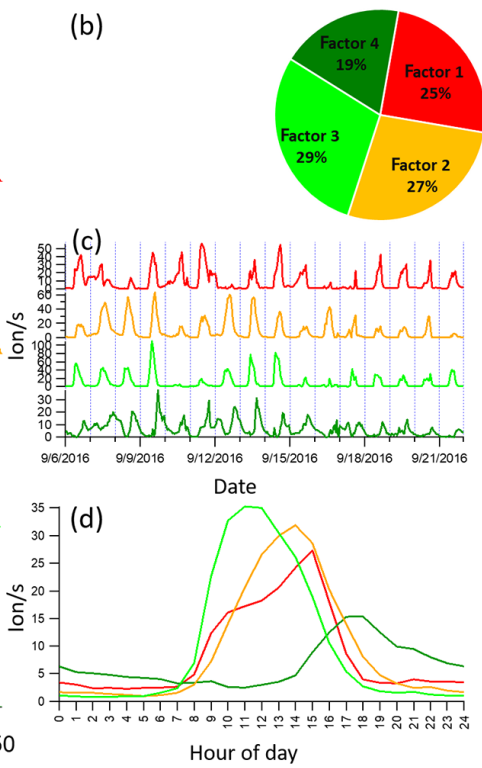

Figure 3. Four-factor result for Range 2 for (a) factor spectral profiles, (b) averaged factor contribution during the campaign, (c) time series, and (d) diurnal trend. Details on the naming schemes for the factors are shown in Table 1.

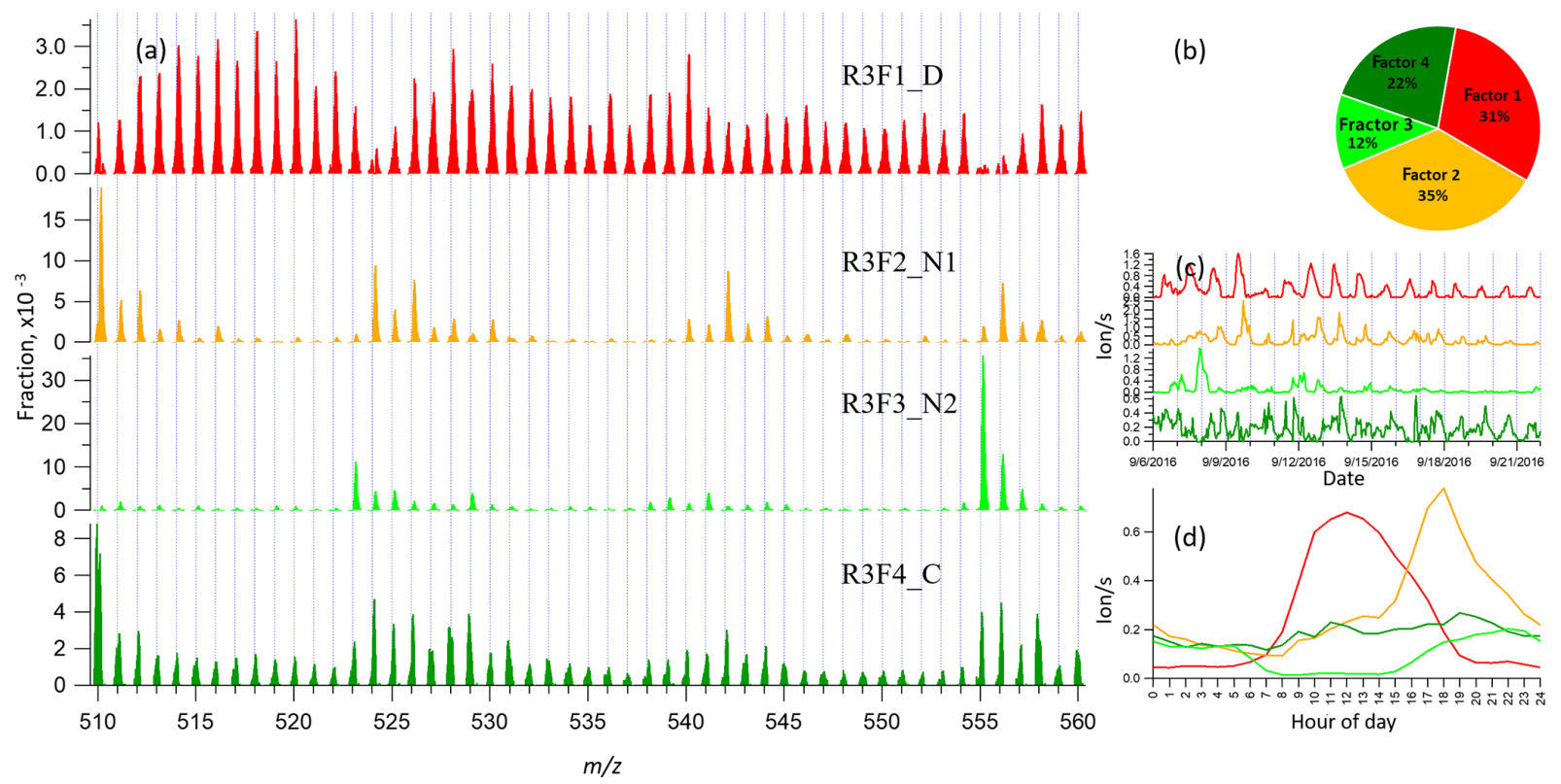

Figure 4. Four-factor result for Range 3 for (a) factor spectral profiles, (b) averaged factor contribution during the campaign, (c) time series, and (d) diurnal trend. Details on the naming schemes for the factors are shown in Table 1.

be expected since the signal intensities in these ranges were much higher than in Range 3. As the number of factors increased (2-10), both the $Q / Q_{\exp }(1.3$ to 0.6$)$ and unexplained variation $(16 \%$ to $8 \%)$ showed a decreasing trend.

In the two-factor result, one daytime factor and one nighttime factor were separated. In the nighttime factor, most masses were found at even masses, and the fraction of masses in Range 3 was much higher than that in the daytime fac- tor. In contrast, in the daytime factor, most masses were observed at odd masses and the fraction of signal in Range 3 was much lower. During the day, photochemical reactions as well as potential emissions increase the concentration of $\mathrm{NO}$, which serves as peroxy radical $\left(\mathrm{RO}_{2}\right)$ terminator and often outcompetes $\mathrm{RO}_{2}$ cross reactions in which dimers can be formed (Ehn et al., 2014). Thus, the production of dimers is suppressed during the day, yielding instead a larger fraction 

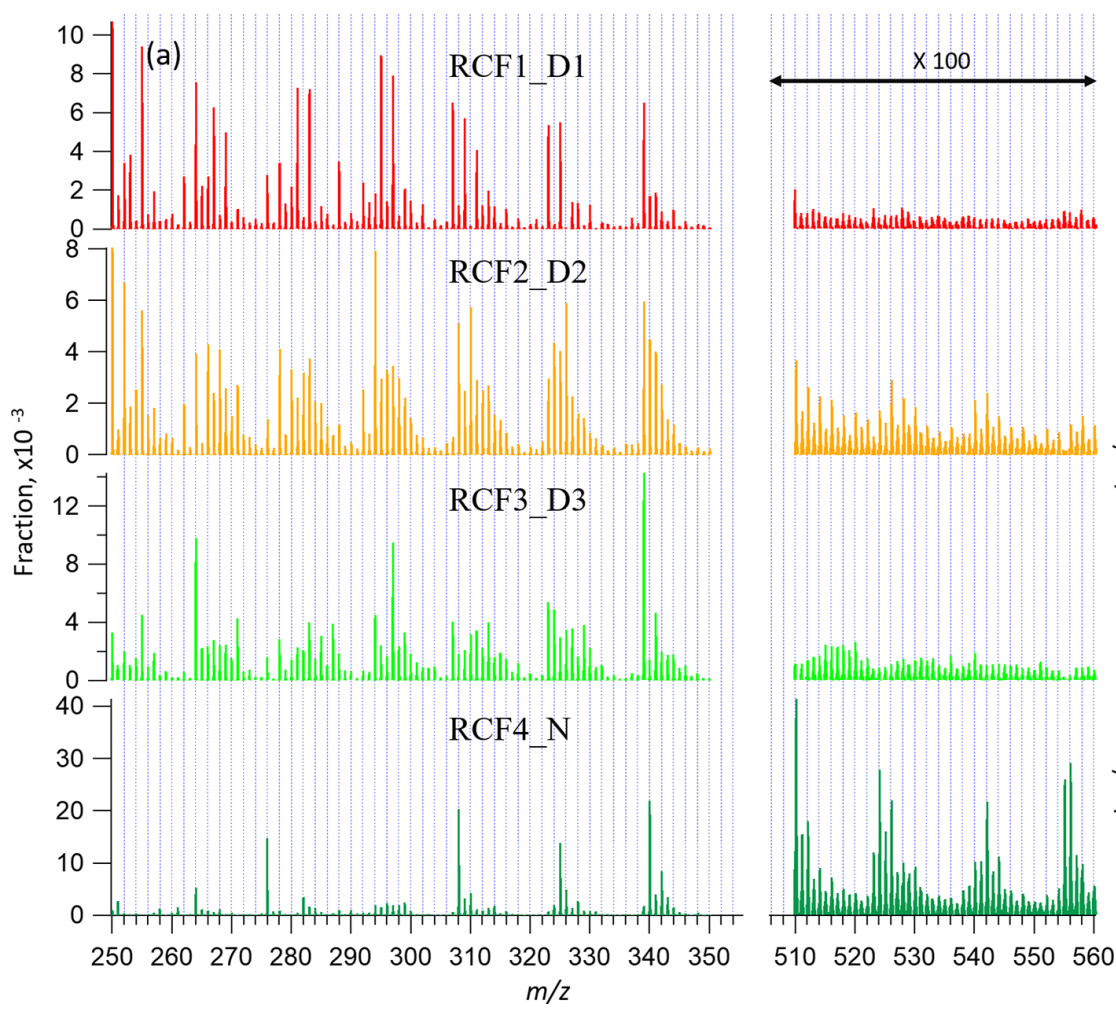

(b)
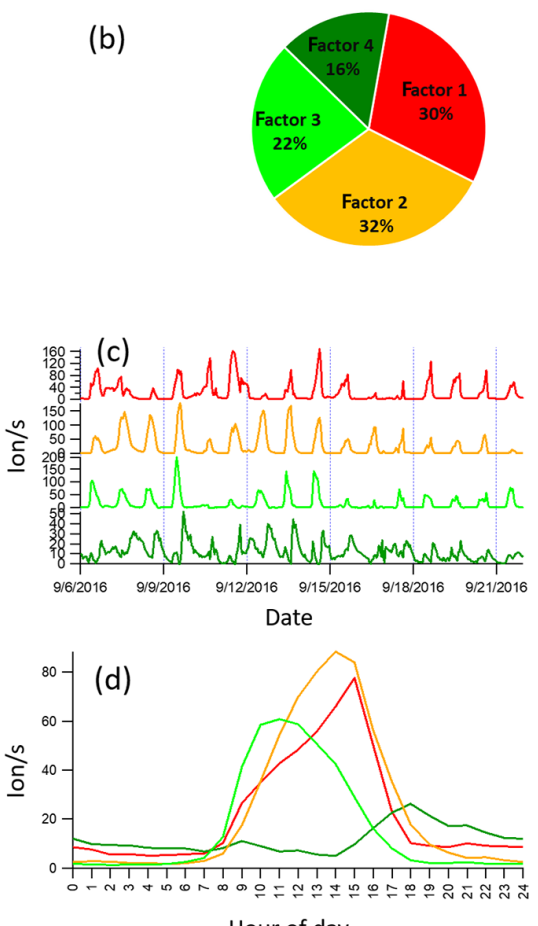

Figure 5. Four-factor result for Range combined for (a) factor spectral profiles, (b) averaged factor contribution during the campaign, (c) time series, and (d) diurnal trend. Details on the naming schemes for the factors are shown in Table 1.

of organic nitrates, as has been shown also previously (Yan et al., 2016).

With the increase in the number of factors, more daytime factors were resolved with different peak times. When the factor number reached seven, a clear sawtooth-shape diurnal cycle occurred, i.e., the contamination factor caused by the zeroing. As more factors were added, no further nighttime factors were separated, and only more daytime factors appeared. To simplify the discussion and inter-range comparison, we also here chose the four-factor result for further analysis. Figure 5 shows the four-factor result of Range combined, with spectral profile, time series, diurnal cycle, and averaged factor contribution during the campaign. The signals in the range of 510-560 Th were enlarged 100 -fold to be visible.

\section{Discussion}

In Sect. 3, results by binPMF analysis were shown for Range 1, Range 2, Range 3, and Range combined. In this section, we discuss and compare the results from the different ranges. To simplify the inter-range comparison, we chose four-factor results for all four ranges, with the abbreviations shown in Table 1. From Range 1, three daytime factors and a contaminations factor were separated. In Range 2, three daytime factors and one nighttime factor (abbreviated as R2F4_N) were resolved. The R2F4_N factor was characterized by signals at $m / z 308 \mathrm{Th}\left(\mathrm{C}_{10} \mathrm{H}_{14} \mathrm{O}_{7} \cdot \mathrm{NO}_{3}^{-}\right), 325 \mathrm{Th}\left(\mathrm{C}_{10} \mathrm{H}_{15} \mathrm{O}_{8} \cdot \mathrm{NO}_{3}^{-}\right)$, and $340 \mathrm{Th}\left(\mathrm{C}_{10} \mathrm{H}_{14} \mathrm{O}_{9} \cdot \mathrm{NO}_{3}^{-}\right)$, and they can be confirmed as monoterpene ozonolysis products (Ehn et al., 2014; Yan et al., 2016). With the increase in factor number to six, the contamination factor was separated also in this mass range. In Range 3, one daytime factor, two nighttime factors, and a contamination factor were separated. The first nighttime factor (R3F2_N1) had large peaks at $m / z 510 \mathrm{Th}\left(\mathrm{C}_{20} \mathrm{H}_{32} \mathrm{O}_{11}\right.$. $\left.\mathrm{NO}_{3}^{-}\right)$and $556 \mathrm{Th}\left(\mathrm{C}_{20} \mathrm{H}_{30} \mathrm{O}_{14} \cdot \mathrm{NO}_{3}^{-}\right)$, representing dimer products that have been identified during chamber studies of monoterpene ozonolysis (Ehn et al., 2014). The molecule observed at $\mathrm{m} / z 510 \mathrm{Th}$ has $32 \mathrm{H}$-atoms, suggesting that one of the $\mathrm{RO}_{2}$ involved would have been initiated by $\mathrm{OH}$, which is formed during the ozonolysis of alkenes such as monoterpenes at nighttime (Atkinson et al., 1992; Paulson and Orlando, 1996). The other nighttime factor (R3F3_N2) was dominated by ions at $m / z 523 \mathrm{Th}\left(\mathrm{C}_{20} \mathrm{H}_{31} \mathrm{O}_{8} \mathrm{NO}_{3} \cdot \mathrm{NO}_{3}^{-}\right)$ and $555 \mathrm{Th}\left(\mathrm{C}_{20} \mathrm{H}_{31} \mathrm{O}_{10} \mathrm{NO}_{3} \cdot \mathrm{NO}_{3}^{-}\right)$, representing nighttime monoterpene oxidation involving $\mathrm{NO}_{3}$. As these dimers contain only one $\mathrm{N}$-atom, and $31 \mathrm{H}$-atoms, we can assume that they are formed from reactions between an $\mathrm{RO}_{2}$ formed from $\mathrm{NO}_{3}$ oxidation and another $\mathrm{RO}_{2}$ formed by ozone oxidation. These results match well with the profiles in a previous study by Yan et al. (2016). The results of Range combined are very similar to Range 2, with one nighttime factor and three day- 
time factors. The contamination factor was separated with increase in factor number to seven.

\subsection{Time series correlation}

In Fig. 6, the upper panels show the time series correlations among the first three ranges. As expected based on the results above, generally the daytime factors, and the two nighttime monoterpene ozonolysis factors (R2F4_N and R3F2_N1), correlated well. However, the contamination factors did not show a strong correlation between different ranges, even though they are undoubtedly from the same source. More about the contamination factors will be discussed in Sect. 4.4. The lower panels in Fig. 6 display the correlations between the first three ranges and the Range combined, and they clearly demonstrate that the results of Range combined are mainly controlled by high signals from Range 1 and 2 . More detailed aspects of the comparison between factors in different ranges is given in the following sections. The good agreements between factors from different subranges also help to verify the robustness of the solutions.

\subsection{Daytime processes}

\subsubsection{Factor comparison}

As mentioned above, with increasing number of factors, more daytime factors will usually be resolved, reflecting the complicated daytime photochemistry. The three daytime factors between Range 1 and Range 2 agreed with each other quite well (Fig. 6a). However, R1F1_D1 and R2F1_D1 did not show strong correlations with the only daytime factor in Range 3 (R3F1_D), while the other two daytime factors in both Range 1 and Range 2, i.e., R1F2_D2, R1F3_D3, and R2F2_D2, R2F3_D3, correlated well with R3F1_D from Range 3.

The first daytime factors from Range 1 and Range 2, R1F1_D1 and R2F1_D1, were mainly characterized by odd masses: 255, 281, 283, 295, 297, 307, 309, 311, 323, 325, and $339 \mathrm{Th}$. The factors are dominated by organonitrates. Organic nitrate formation during daytime is generally associated with the termination of $\mathrm{RO}_{2}$ radicals by NO. This termination step is mutually exclusive with the termination of $\mathrm{RO}_{2}$ with other $\mathrm{RO}_{2}$, which can lead to dimer formation. If the NO concentration is the limiting factor for the formation of these factors, the low correlations between the NOterminated monomer factors and the dimer factors are to be expected. In contrast, if the other daytime factors mainly depend on oxidant and monoterpene concentrations, some correlation between those, and the daytime dimer factor, is to be expected, as shown in Fig. $6 \mathrm{~b}$ and c.

All the spectral profiles resolved from Range combined binPMF analysis inevitably contained mass contributions from $m / z 510$ to $560 \mathrm{Th}$, even the daytime factor from Range combined (RCF1_D1) which did not show a clear correlation with R3F1_D from Range 3 (Fig. 6e).

The second and third daytime factors in Range 1 and Range 2, R1F2_D2, R1F3_D3, R2F2_D2, R2F3_D3, had high correlations with R3F1_D in Range 3. Daytime factors in Range combined (RCF2_D2 and RCF3_D3) also showed good correlation with R3F1_D in Range 3. However, if we compare R3F1_D and the mass range of $m / z 510-560 \mathrm{Th}$ of the daytime factors in Range combined, just with a quick look, we can readily see the difference. The daytime factor separated in Range 3 (R3F1_D) has no obvious markers in the profile. With the increase in factor number (up to 10 factors), no clearly new factors were separated in Range 3, but instead the previously separated factors were seen to split into several factors. However, the spectral pattern in R3F1_D is different from that in the mass range of 510-560 Th in RCF2_D2. The factorization of Range combined was mainly controlled by low masses due to their high signals. The signals at high masses were forced to be distributed according to the time series determined by small masses. Ultimately, this will lead to failure in factor separation for this low-signal range.

\subsubsection{Daytime dimer formation}

Dimers are primarily produced during nighttime, due to $\mathrm{NO}$ suppressing $\mathrm{RO}_{2}+\mathrm{RO}_{2}$ reactions in daytime (Ehn et al., 2014; Yan et al., 2016). However, in this study, we found one clear daytime factor in Range 3 (R3F1_D, peak at local time 12:00, UTC +2 ) by subrange analysis. With high loadings from even masses including 516, 518, 520, 528, and $540 \mathrm{Th}$, this only daytime factor in dimer range correlated very well with two daytime factors in Range 1 and Range 2 (R1F2_D2, R1F3_D3, R2F2_D2, R2F3_D3) (Fig. 6b and c). Table 2 includes the correlation matrix of all PMF and factors and selected meteorological parameters. Strong correlation between R3F1_D with solar radiation was found, with $R=0.79$ (Table 2). This may indicate involvement of $\mathrm{OH}$ oxidation in producing this factor.

As previous studies have shown, dimers greatly facilitate new particle formation (NPF) (Kirkby et al., 2016; Troestl et al., 2016; Lehtipalo et al., 2018), and this daytime dimer factor may represent a source of dimers that would impact the initial stages of NPF in Hyytiälä. Mohr et al. (2017) reported a clear diel pattern of dimers (sum of about 60 dimeric compounds of $\mathrm{C}_{16-20} \mathrm{H}_{13-33} \mathrm{O}_{6-9}$ ) during NPF events in 2013 in Hyytiälä, with minimum at night and maximum after noon, and they estimated that these dimers can contribute $\sim 5 \%$ of the mass of sub- $60 \mathrm{~nm}$ particles. The link between the dimers presented in that paper and those reported here will require further studies, as will the proper quantification of the dimer factor identified here. 
Table 1. Summary of PMF results for the different mass ranges.

\begin{tabular}{|c|c|c|c|c|}
\hline Range & Factor number & Factor name ${ }^{\mathrm{a}}$ & Dominant peaks & Peak time \\
\hline \multirow[t]{4}{*}{ Range $1(250-300 \mathrm{Th})$} & 1 & R1F1_D1 & $250,255,295,297$ & $15: 00$ \\
\hline & 2 & R1F2_D2 & $250,252,294$ & $15: 00$ \\
\hline & 3 & R1F3_D3 & 264,297 & 11:00 \\
\hline & 4 & R1F4_C & 276 & $-\mathrm{b}$ \\
\hline \multirow[t]{4}{*}{ Range $2(300-350 \mathrm{Th})$} & 1 & R2F1_D1 & $307,309,323,325,339$ & $15: 00$ \\
\hline & 2 & R2F2_D2 & $310,326,339$ & $14: 00$ \\
\hline & 3 & R2F3_D3 & 339 & 11:00 \\
\hline & 4 & R2F4_N & $308,325,340$ & 18:00 \\
\hline \multirow[t]{4}{*}{ Range 3 (510-560 Th) } & 1 & R3F1_D & $516,518,520,528,540$ & $12: 00$ \\
\hline & 2 & R3F2_N1 & $510,524,542,556$ & 18:00 \\
\hline & 3 & R3F3_N2 & 523,555 & $22: 00$ \\
\hline & 4 & R3F4_C & 510,558 & $-\mathrm{b}$ \\
\hline \multirow[t]{4}{*}{ Range combined $(1,2,3)$} & 1 & RCF1_D1 & $250,255,295,339$ & $15: 00$ \\
\hline & 2 & RCF2_D2 & $250,252,294,339$ & $14: 00$ \\
\hline & 3 & RCF3_D3 & $264,297,339$ & 11:00 \\
\hline & 4 & RCF4_N & $308,340,510,524,555,556$ & 18:00 \\
\hline
\end{tabular}

${ }^{\mathrm{a}}$ Factor name is defined with range name, factor number, and name. For example, RxFy represents factor $y$ in range $x$. RC stands for Range combined. For the factor name, $\mathrm{D}$ is short for daytime, $\mathrm{N}$ for nighttime, and $\mathrm{C}$ for contamination. ${ }^{\mathrm{b}}$ The contamination factor in Range 1 shows a sawtooth pattern, while Range 3 shows no diurnal pattern.

(a)
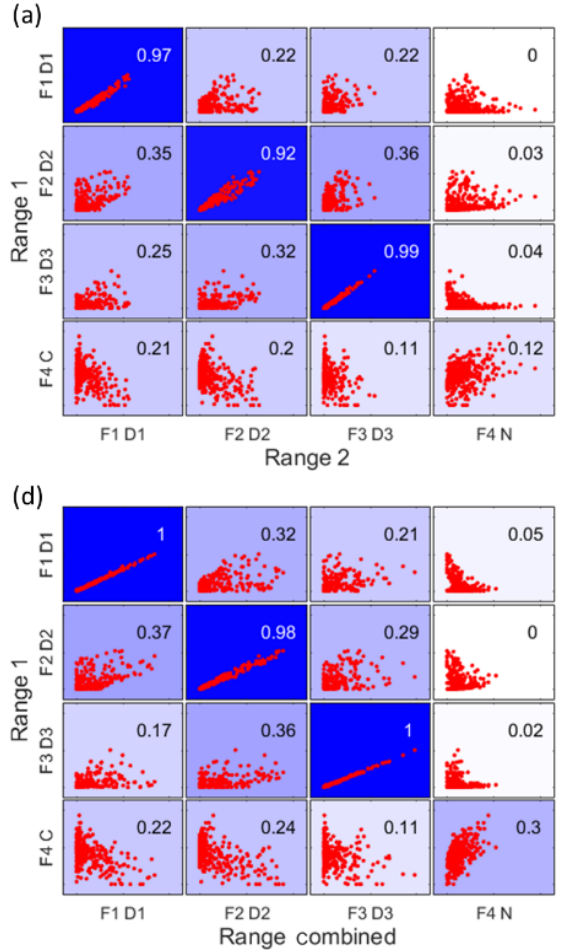

(b)
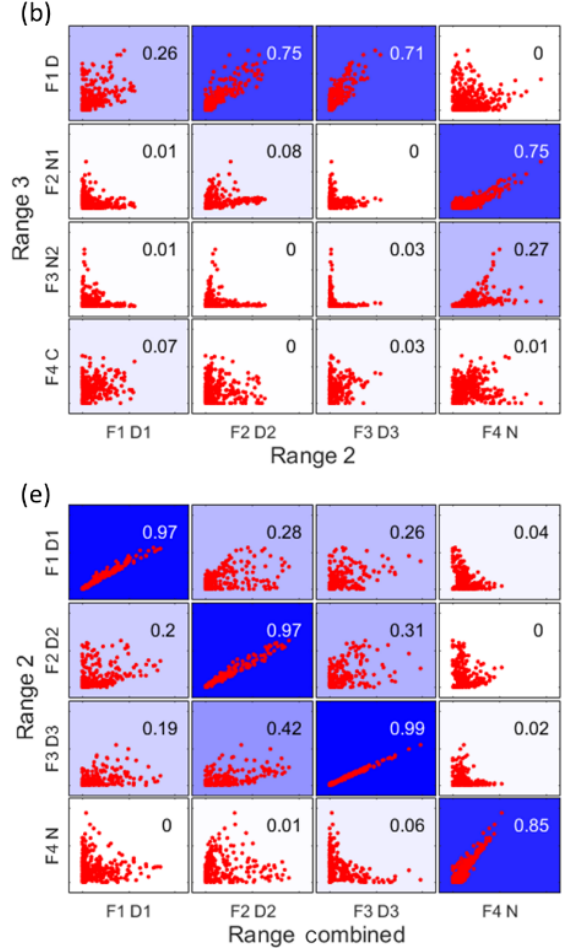

(c)

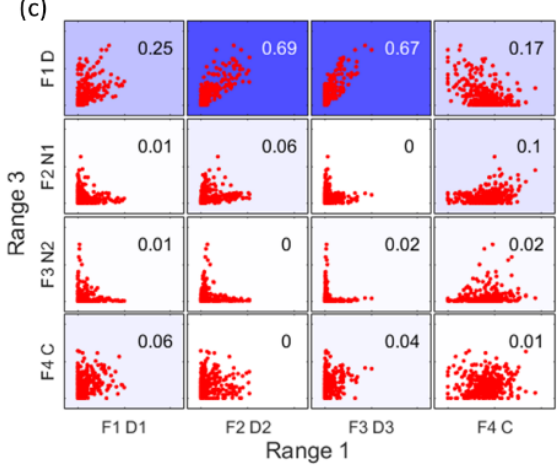

(f)

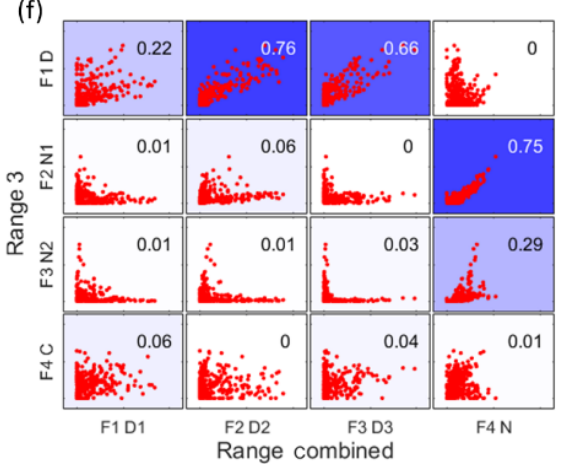

Figure 6. Time series correlations among Range 1, Range 2, Range 3 (a-c), and between the first three ranges and the Range combined (d-f). The abbreviations for different factors are the same as in Table 1, with $\mathrm{F}$ for factor, $\mathrm{D}$ for daytime, $\mathrm{N}$ for nighttime, and $\mathrm{C}$ for contamination, e.g. F1D1 for factor 1 daytime 1 . The coefficient of determination, $R^{2}$, is marked in each subplot by a number shown in the right upper corners and by the blue colors, with stronger blue indicating higher $R^{2}$. 
Table 2. Correlation between factors and meteorological parameters and gases.

\begin{tabular}{|c|c|c|c|c|c|c|c|c|c|c|c|c|c|c|c|c|}
\hline & $\begin{array}{c}\text { R1F1 } \\
\text { D1 }\end{array}$ & $\begin{array}{c}\text { R1F1 } \\
\text { D2 }\end{array}$ & $\begin{array}{c}\text { R1F1 } \\
\text { D3 }\end{array}$ & $\begin{array}{c}\text { R1F1 } \\
\text { C }\end{array}$ & $\begin{array}{c}\mathrm{R} 2 \mathrm{~F} 1 \\
\mathrm{D} 1 \\
\end{array}$ & $\begin{array}{l}\mathrm{R} 2 \mathrm{~F} 2 \\
\mathrm{D} 2\end{array}$ & $\begin{array}{c}\text { R2F3 } \\
\text { D3 } \\
\end{array}$ & $\begin{array}{c}\text { R2F4 } \\
\text { N }\end{array}$ & $\begin{array}{c}\text { R3F1 } \\
\text { D }\end{array}$ & $\begin{array}{c}\text { R3F2 } \\
\text { N1 }\end{array}$ & $\begin{array}{l}\mathrm{R} 3 \mathrm{~F} 3 \\
\mathrm{~N} 2 \\
\end{array}$ & $\begin{array}{c}\text { R3F4 } \\
\text { C }\end{array}$ & $\begin{array}{c}\text { RCF1 } \\
\text { D1 }\end{array}$ & $\begin{array}{c}\mathrm{RCF} 2 \\
\mathrm{D} 2\end{array}$ & $\begin{array}{c}\mathrm{RCF} 3 \\
\text { D3 }\end{array}$ & $\begin{array}{c}\text { RCF4 } \\
\text { N }\end{array}$ \\
\hline $\mathrm{O}_{3}$ & 0.51 & 0.59 & 0.35 & -0.18 & 0.47 & 0.57 & 0.36 & 0.43 & 0.55 & 0.33 & 0.27 & 0.22 & 0.49 & 0.57 & 0.33 & 0.34 \\
\hline NO & 0.13 & -0.01 & 0.24 & -0.03 & 0.18 & -0.02 & 0.24 & -0.22 & 0.13 & -0.19 & -0.17 & 0.03 & 0.13 & 0.00 & 0.26 & -0.18 \\
\hline $\mathrm{NOx}$ & -0.05 & -0.22 & -0.10 & 0.09 & -0.01 & -0.23 & -0.11 & -0.13 & -0.16 & -0.21 & -0.04 & 0.04 & -0.04 & -0.22 & -0.09 & -0.11 \\
\hline $\mathrm{RH}$ & -0.46 & -0.80 & -0.63 & 0.30 & -0.43 & -0.82 & -0.64 & -0.27 & -0.78 & -0.39 & -0.07 & -0.07 & -0.43 & -0.82 & -0.60 & -0.21 \\
\hline $\mathrm{T}$ & 0.66 & 0.72 & 0.40 & -0.24 & 0.65 & 0.66 & 0.41 & 0.39 & 0.65 & 0.30 & 0.14 & 0.19 & 0.66 & 0.68 & 0.38 & 0.24 \\
\hline UVB & 0.52 & 0.63 & 0.82 & -0.40 & 0.52 & 0.68 & 0.84 & -0.30 & 0.79 & -0.08 & -0.27 & 0.08 & 0.49 & 0.68 & 0.83 & -0.29 \\
\hline
\end{tabular}

\subsection{Nighttime processes}

\subsubsection{Factor comparison}

Since high-mass dimers are more likely to form at night due to photochemical production of NO in daytime, which inhibits $\mathrm{RO}_{2}+\mathrm{RO}_{2}$ reactions, Range 3 had the highest fraction of nighttime signals of all the subranges. While Range 3 produced two nighttime factors, Range 2 and Range combined showed one, and Range 1 had no nighttime factor. The difference between the two results also indicates the advantage of analyzing monomers and dimers separately.

The two nighttime factors in Range 3 can be clearly identified as arising from ozonolysis (R3F2_N1) and a mix of ozonolysis and $\mathrm{NO}_{3}$ oxidation (R3F2_N2) based on the mass spectral profiles, as described above. The organonitrate at $m / z 555 \mathrm{Th}, \mathrm{C}_{20} \mathrm{H}_{31} \mathrm{O}_{10} \mathrm{NO}_{3} \cdot \mathrm{NO}_{3}^{-}$, is a typical marker for $\mathrm{NO}_{3}$ radical-initiated monoterpene chemistry (Yan et al., 2016). However, several interesting features become evident when comparing to the results of Range 2 and Range combined. Firstly, only one nighttime factor (R2F4_N, RCF4_N) was separated in each of these ranges, and that shows a clear resemblance with ozonolysis of monoterpenes as measured in numerous studies, e.g., Ehn et al. (2012, 2014). Secondly, the high correlation found in Fig. $6 \mathrm{~b}$ between the ozonolysis factors (i.e., R2F4_N, R3F2_N1, RCF4_N) further supports the assignment. However, factor R2F4_N is the only nighttime factor in the monomer range, suggesting that $\mathrm{NO}_{3}$ radical chemistry of monoterpenes in Hyytiälä does not form substantial amounts of HOM monomers. The only way for the CI-APi-TOF to detect products of monoterpene- $\mathrm{NO}_{3}$ radical chemistry may thus be through the dimers, where one highly oxygenated $\mathrm{RO}_{2}$ radical from ozonolysis reacts with a less oxygenated $\mathrm{RO}_{2}$ radical from $\mathrm{NO}_{3}$ oxidation.

In the results by Yan et al. (2016) the combined UMRPMF of monomers and dimers did yield a considerable amount of compounds in the monomer range also for the $\mathrm{NO}_{3}$ radical chemistry factor. There may be several reasons for this discrepancy. One major cause for differences be- tween the spring dataset by Yan et al. (2016) and the autumn dataset presented here is that nighttime concentrations of HOMs were greatly reduced during our autumn campaign. The cause may have been fairly frequent fog formation during nights and also the fact that the concentration of ozone decreased nearly to zero during several nights (Zha et al., 2018). It is also possible that the $\mathrm{NO}_{3}$ radical-related factor by Yan et al. (2016) is probably a mixture of $\mathrm{NO}_{3}$ and $\mathrm{O}_{3}$ radical chemistry, while the monomer may thus be attributed to the $\mathrm{O}_{3}$ part. Alternatively, the different conditions during the two measurement periods, as well as seasonal difference in monoterpene mixtures (Hakola et al., 2012), caused variations in the oxidation pathways.

\subsubsection{Dimers initiated by $\mathrm{NO}_{3}$ radicals}

Previous studies show that $\mathrm{NO}_{3}$ oxidation of $\alpha$-pinene, the most abundant monoterpene in Hyytiälä (Hakola et al., 2012), produces fairly little SOA mass (yields $<4 \%$ ), while $\beta$-pinene shows yields of up to $53 \%$ (Bonn and Moorgat, 2002; Nah et al., 2016). The $\mathrm{NO}_{3}+\beta$-pinene reaction results in low-volatility organic nitrate compounds with carboxylic acid, alcohol, and peroxide functional groups (Fry et al., 2014; Boyd et al., 2015), while the $\mathrm{NO}_{3}+\alpha$-pinene reaction will typically lose the nitrate functional group and form oxidation products with high vapor pressures (Spittler et al., 2006; Perraud et al., 2010). Most monoterpene-derived HOMs, including monomers, are low-volatility molecules (Peräkylä et al., 2020), and thus a low SOA yield indicates a low HOM yield. Thus, while there are to our knowledge no laboratory studies on HOM formation from $\mathrm{NO}_{3}$ oxidation of $\alpha$-pinene, a low yield can be expected based on SOA studies.

As discussed above, a dimer factor (R3F2_N2) was identified as being a crossover between $\mathrm{RO}_{2}$ radicals initiated by $\mathrm{NO}_{3}$ radicals and $\mathrm{O}_{3}$. Figure 7 shows the time series of this factor, as well as the products of $\left[\mathrm{NO}_{3}\right]^{2} \times$ $[\text { monoterpene }]^{2},\left[\mathrm{O}_{3}\right]^{2} \times[\text { monoterpene }]^{2}$, and $\left[\mathrm{NO}_{3}\right] \times\left[\mathrm{O}_{3}\right]$ $\times[\text { monoterpene }]^{2}$. These products are used to mimic the for- 

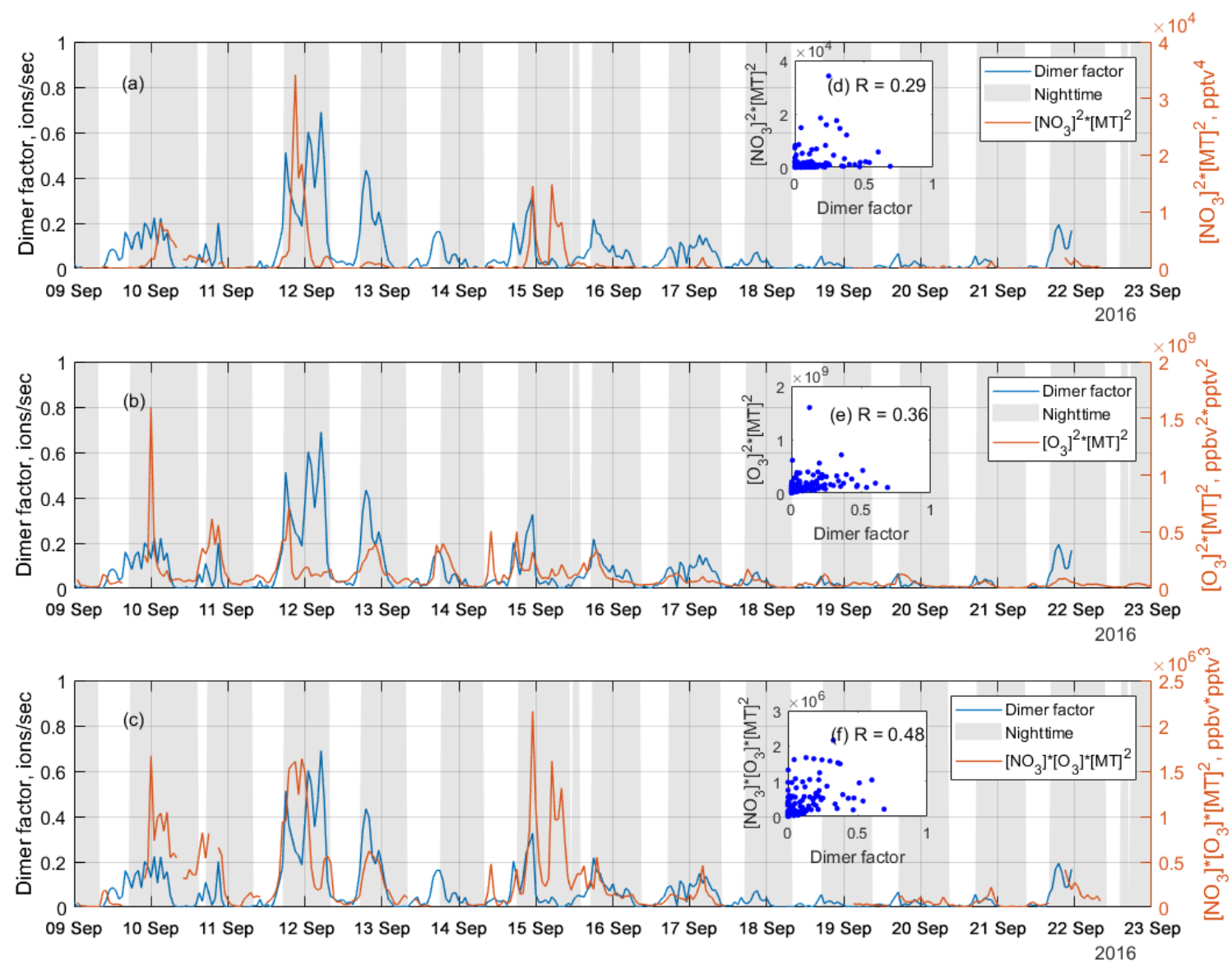

Figure 7. Time series of the $\mathrm{NO}_{3}$ oxidation dimer factor (blue line) and the products of (a) $\left[\mathrm{NO}_{3}\right]^{2} \times[\text { monoterpene }]^{2}$, (b) $\left[\mathrm{O}_{3}\right]^{2} \times$ [monoterpene $]^{2}$, and $(\mathbf{c})\left[\mathrm{NO}_{3}\right] \times\left[\mathrm{O}_{3}\right] \times[\text { monoterpene }]^{2}$, where [] represents concentration in units of pptv for $\mathrm{NO}_{3}$ radicals and monoterpene and ppbv for $\mathrm{O}_{3}$, while the scatter plots are shown as inserts, (d), (e), and (f), respectively. The scatter plots and correlation coefficients, $R$, are only calculated from nighttime data, which is selected based on solar radiation, to eliminate the influence from daytime oxidation processes.

mation rates of the $\mathrm{RO}_{2}$ radicals reacting to form the dimers, either from pure $\mathrm{NO}_{3}$ oxidation (Fig. 7a), pure $\mathrm{O}_{3}$ oxidation (Fig. 7b), or the mixed reaction between $\mathrm{RO}_{2}$ from the two oxidants (Fig. 7c). The $\mathrm{NO}_{3}$ concentration was estimated in Liebmann et al. (2018) for the same campaign. Monoterpenes were measured using a proton transfer reaction timeof-flight mass spectrometer (PTR-TOF-MS). More details on measurement of $\mathrm{NO}_{3}$ proxy and monoterpene can be found in Liebmann et al. (2018).

As shown in Fig. 7, the time series of the dimer factor tracks those of $\left[\mathrm{NO}_{3}\right]^{2} \times[\text { monoterpene }]^{2}$ and $\left[\mathrm{O}_{3}\right]^{2} \times$ $[\text { monoterpene }]^{2}$ reasonably well, but it shows the highest correlation with the product of $\left[\mathrm{NO}_{3}\right] \times\left[\mathrm{O}_{3}\right] \times[\text { monoterpene }]^{2}$. This further supports this dimer formation as a mixed process of ozonolysis and $\mathrm{NO}_{3}$ oxidation. The heterogeneity of the monoterpene emissions in the forest, and the fact that no dimer loss process is included, partly explains the relatively low correlation coefficients. The sampling inlets for PTRTOF were about $170 \mathrm{~m}$ away from the $\mathrm{NO}_{3}$ reactivity mea- surement (Liebmann et al., 2018), which in turn was some tens of meters away from the HOM measurements. Thus, this analysis should be considered qualitative only.

The nitrate dimer factor (R3F2_N2) was dominated by the organonitrate at $m / z 555 \mathrm{Th}, \mathrm{C}_{20} \mathrm{H}_{31} \mathrm{O}_{10} \mathrm{NO}_{3} \cdot \mathrm{NO}_{3}^{-}$. However, unlike the pure ozonolysis dimer factor which had a corresponding monomer factor $(R=0.86$ between factor R2F4_N and R3F2_N1), this $\mathrm{NO}_{3}$-related dimer factor did not have an equivalent monomer factor. This suggests that the $\mathrm{NO}_{3}$ oxidation of the monoterpene mixture in Hyytiälä does not by itself form much HOMs, but, in the presence of $\mathrm{RO}_{2}$ from ozonolysis, the $\mathrm{RO}_{2}$ from $\mathrm{NO}_{3}$ oxidation can take part in HOM dimer formation. This further implies that, unlike previous knowledge based on single-oxidant experiments in chambers, $\mathrm{NO}_{3}$ oxidation may have a larger impact on SOA formation in the atmosphere where different oxidants exist concurrently. This highlights the need for future laboratory studies to consider systems with multiple oxidants during monoterpene oxidation experiments to truly understand the 
role and contribution of different oxidants and $\mathrm{NO}_{3}$ in particular.

\subsection{Fluorinated compounds}

During the campaign, an automated instrument zeroing every $3 \mathrm{~h}$ was conducted. While the zeroing successfully removed the low-volatility $\mathrm{HOMs}$ and $\mathrm{H}_{2} \mathrm{SO}_{4}$, the process also introduced contaminants into the inlet lines, e.g., perfluorinated organic acids from Teflon tubing. Each zeroing process lasted for $10 \mathrm{~min}$. In the data analysis, we removed all the $10 \mathrm{~min}$ zeroing periods, and averaged the data to $1 \mathrm{~h}$ time resolution, but contaminants were still identified in all ranges by binPMF. However, the correlation between contamination factors from different ranges is low (Fig. 6c).

To further investigate the low factor correlations of the same source, three fluorinated compounds with different volatilities, $\left(\mathrm{CF}_{2}\right)_{3} \mathrm{CO}_{2} \mathrm{HF} \cdot \mathrm{NO}_{3}^{-}(275.9748 \mathrm{Th})$, $\left(\mathrm{CF}_{2}\right)_{5} \mathrm{C}_{2} \mathrm{O}_{4} \mathrm{H}^{-}(338.9721 \mathrm{Th})$, and $\left(\mathrm{CF}_{2}\right)_{6} \mathrm{CO}_{2} \mathrm{HF} \cdot \mathrm{NO}_{3}^{-}$ $(425.9653 \mathrm{Th})$, were examined in fine time resolution, i.e., $1 \mathrm{~min}$. The time series and $3 \mathrm{~h}$ cycle of the three fluorinated compounds were shown in Figs. S3 and S4. The correlation coefficients dropped greatly before and after the zero period was removed: from 0.9 to 0.3 for $R^{2}$ between $m / z 276$ and $339 \mathrm{Th}$ and 0.8 to 0.1 between $\mathrm{m} / z 276$ and $426 \mathrm{Th}$ (Fig. S5a, b). A similar effect is also found with the $1 \mathrm{~h}$ averaged data (Fig. S5c, d). It is evident that the three fluorinated compounds were from the same source (zeroing process), but due to their different volatilities, they were lost at different rates. This, in turn, means that the spectral signature of this source will change as a function of time, at odds with one of the basic assumptions of PMF.

The analysis of the fluorinated compounds in our system was here merely used as an example to show that volatility can impact source profiles over time. In Fig. S5, it can be clearly seen that the profile of Range combined is noisier than that of Range 3, probably due to the varied fractional contributions of contamination compounds to the profile. In ambient data, products from different sources can have undergone atmospheric processing, altering the product distribution. This analysis highlighted the importance of differences in the sink terms due to different volatilities of the products. This may be an important issue for gas-phase mass spectrometry analysis, potentially underestimated by many PMF users, as it is likely only a minor issue for aerosol data, for which PMF has been applied much more routinely. If failing to achieve physically meaningful factors using PMF on gas-phase mass spectra, our recommendation is to try applying PMF to subranges of the spectrum, where intermediatevolatility organic compounds (IVOCs), semivolatile organic compounds (SVOCs), and (extremely) low volatility organic compounds ((E)LVOCs) could be analyzed separately.

\subsection{Atmospheric insights}

Based on the new data analysis technique, binPMF, applied to subranges of mass spectra, we were able to separate two particularly intriguing atmospheric processes, the formation of daytime dimers and dimer formation involving $\mathrm{NO}_{3}$ radicals, which otherwise could not have been identified in our study.

With a diurnal peak around noontime, the daytime dimers identified in this study correlate very well with daytime factors in the monomer range. Strong correlation between this factor and solar radiation indicates the potential role of $\mathrm{OH}$ oxidation in the formation of daytime dimers. By now, very few studies have reported the observations of daytime dimers. As dimers are shown to be able to take part in new particle formation (NPF) (Kirkby et al., 2016), this daytime dimer may contribute to the early stages of NPF in the boreal forest.

The second process identified in our study is the formation of dimers that are a crossover between $\mathrm{NO}_{3}$ and $\mathrm{O}_{3}$ oxidation. Such dimers have been identified before (Yan et al., 2016). However, we were not able to identify corresponding HOM monomer compounds. This finding indicates that while $\mathrm{NO}_{3}$ oxidation of the monoterpenes in Hyytiälä may not undergo autoxidation to form HOMs by themselves, they can contribute to $\mathrm{HOM}$ dimers when the $\mathrm{NO}_{3}$-derived $\mathrm{RO}_{2}$ reacts with highly oxygenated $\mathrm{RO}_{2}$ from other oxidants. Multi-oxidant systems should be taken into consideration in future experimental studies on monoterpene oxidation processes.

\section{Conclusions}

The recent developments in the field of mass spectrometry, combined with factor analysis techniques such as PMF, have greatly improved our understanding of complicated atmospheric processes and sources. In this study, we applied the new binPMF approach (Zhang et al., 2019) to separate subranges of mass spectra measured using a chemical ionization mass spectrometer in the Finnish boreal forest. By using this method, we were able to identify a daytime dimer factor, presumably initiated by $\mathrm{OH} / \mathrm{O}_{3}$ oxidation of monoterpenes, forming from $\mathrm{RO}_{2}+\mathrm{RO}_{2}$ reactions despite competition from daytime NO. This compound group, showing a diurnal peak around noon, may contribute to new particle formation at the site. In addition, we successfully separated $\mathrm{NO}_{3}$-related dimers which would not have been identified from this dataset without utilizing the different subranges. The $\mathrm{NO}_{3}$-related factor was consistent with earlier observations (Yan et al., 2016), with the exception that we did not observe any corresponding monomer factor. This may be explained by the observed nitrate-containing dimers being formed from two $\mathrm{RO}_{2}$ radicals, where one is initiated by oxidation by $\mathrm{O}_{3}$ and the other by $\mathrm{NO}_{3}$. If the $\mathrm{NO}_{3}$-derived $\mathrm{RO}_{2}$ 
radicals are not able to form HOMs by themselves, there will not be any related monomers observed. To validate this hypothesis, future laboratory experiments that target more complex oxidation systems will be useful in order to understand the role of $\mathrm{NO}_{3}$ oxidation in SOA formation under different atmospheric conditions.

Apart from these two major findings, we also found several other benefits of applying PMF on separate subranges of the mass spectra. First, different compounds from the same source can have variable loss rates due to differences in volatilities. This leads to increased difficulty for PMF to separate this source, but if the PMF analysis is run separately on lighter masses (with higher volatility) and heavier masses (with lower volatility), the source may become easier to distinguish. Secondly, chemistry or sources contributing only to one particular mass range, e.g., dimers, can be better separated. Thirdly, mass ranges with small, but informative, signals can be more accurately assigned as their contribution becomes larger than if the entire mass range was analyzed at once. Finally, running PMF on separate mass ranges also allows for comparing the factors between the different ranges, helping to verify the results. In summary, while we do not suggest that this type of subrange analysis should always be utilized, we recommend other analysts of gas-phase mass spectrometer data to test this approach in order to see whether additional useful information can be obtained. In our dataset, this method was crucial for identifying different types of dimers and dimer formation pathways, which are of great importance for the formation of both new particles and SOA.

Data availability. The data used in this study are available from the first author upon request: please contact Yanjun Zhang (yanjun.zhang@helsinki.fi).

Supplement. The supplement related to this article is available online at: https://doi.org/10.5194/acp-20-5945-2020-supplement.

Author contributions. ME and YZ designed the study. QZ and MR collected the data; data analysis and article writing were done by YZ. All coauthors discussed the results and commented on the article.

Competing interests. The authors declare that they have no conflict of interest.

Acknowledgements. We thank the tofTools team for providing tools for mass spectrometry data analysis. The personnel of the Hyytiälä forestry field station are acknowledged for help during field measurements.
Financial support. This research has been supported by the European Research Council (grant no. 638703-COALA), the Academy of Finland (grant nos. 317380 and 320094), and the Swiss National Science postdoc mobility grant (grant no. P2EZP2_181599).

Open access funding provided by Helsinki University Library.

Review statement. This paper was edited by James Allan and reviewed by two anonymous referees.

\section{References}

Allan, J. D., Jimenez, J. L., Williams, P. I., Alfarra, M. R., Bower, K. N., Jayne, J. T., Coe, H., and Worsnop, D. R.: Quantitative sampling using an Aerodyne aerosol mass spectrometer 1. Techniques of data interpretation and error analysis, J. Geophys. Res.Atmos., 108, https://doi.org/10.1029/2002JD002358, 2003.

Atkinson, R., Aschmann, S. M., Arey, J., and Shorees, B.: Formation of $\mathrm{OH}$ radicals in the gas phase reactions of $\mathrm{O}_{3}$ with a series of terpenes, J. Geophys. Res., 97, 6065-6073, https://doi.org/10.1029/92jd00062, 1992.

Berndt, T., Mentler, B., Scholz, W., Fischer, L., Herrmann, H., Kulmala, M., and Hansel, A.: Accretion Product Formation from Ozonolysis and $\mathrm{OH}$ Radical Reaction of $\alpha$ Pinene: Mechanistic Insight and the Influence of Isoprene and Ethylene, Environ. Sci. Technol., 52, 11069-11077, https://doi.org/10.1021/acs.est.8b02210, 2018a.

Berndt, T., Scholz, W., Mentler, B., Fischer, L., Herrmann, H., Kulmala, M., and Hansel, A.: Accretion Product Formation from Self- and Cross-Reactions of $\mathrm{RO}_{2}$ Radicals in the Atmosphere, Angewandte Chemie International Edition in English, 57, 38203824, https://doi.org/10.1002/anie.201710989, 2018b.

Bertram, T. H., Kimmel, J. R., Crisp, T. A., Ryder, O. S., Yatavelli, R. L. N., Thornton, J. A., Cubison, M. J., Gonin, M., and Worsnop, D. R.: A field-deployable, chemical ionization timeof-flight mass spectrometer, Atmos. Meas. Tech., 4, 1471-1479, https://doi.org/10.5194/amt-4-1471-2011, 2011.

Bianchi, F., Kurtén, T., Riva, M., Mohr, C., Rissanen, M. P., Roldin, P., Berndt, T., Crounse, J. D., Wennberg, P. O., Mentel, T. F., Wildt, J., Junninen, H., Jokinen, T., Kulmala, M., Worsnop, D. R., Thornton, J. A., Donahue, N., Kjaergaard, H. G., and Ehn, M.: Highly Oxygenated Organic Molecules (HOM) from GasPhase Autoxidation Involving Peroxy Radicals: A Key Contributor to Atmospheric Aerosol, Chem. Rev., 119, 3472-3509, https://doi.org/10.1021/acs.chemrev.8b00395, 2019.

Bonn, B. and Moorgat, G. K.: New particle formation during a- and b-pinene oxidation by $\mathrm{O}_{3}, \mathrm{OH}$ and $\mathrm{NO}_{3}$, and the influence of water vapour: particle size distribution studies, Atmos. Chem. Phys., 2, 183-196, https://doi.org/10.5194/acp-2183-2002, 2002.

Boyd, C. M., Sanchez, J., Xu, L., Eugene, A. J., Nah, T., Tuet, W. Y., Guzman, M. I., and Ng, N. L.: Secondary organic aerosol formation from the $\beta$-pinene $+\mathrm{NO}_{3}$ system: effect of humidity and peroxy radical fate, Atmos. Chem. Phys., 15, 7497-7522, https://doi.org/10.5194/acp-15-7497-2015, 2015.

Canagaratna, M., Jayne, J., Jimenez, J., Allan, J., Alfarra, M., Zhang, Q., Onasch, T., Drewnick, F., Coe, H., and Middle- 
brook, A.: Chemical and microphysical characterization of ambient aerosols with the aerodyne aerosol mass spectrometer, Mass Spectrom. Rev., 26, 185-222, 2007.

Canonaco, F., Crippa, M., Slowik, J. G., Baltensperger, U., and Prévôt, A. S. H.: SoFi, an IGOR-based interface for the efficient use of the generalized multilinear engine (ME2) for the source apportionment: ME-2 application to aerosol mass spectrometer data, Atmos. Meas. Tech., 6, 3649-3661, https://doi.org/10.5194/amt-6-3649-2013, 2013.

Craven, J. S., Yee, L. D., Ng, N. L., Canagaratna, M. R., Loza, C. L., Schilling, K. A., Yatavelli, R. L. N., Thornton, J. A., Ziemann, P. J., Flagan, R. C., and Seinfeld, J. H.: Analysis of secondary organic aerosol formation and aging using positive matrix factorization of high-resolution aerosol mass spectra: application to the dodecane low-NO $\mathrm{NO}_{\mathrm{x}}$ system, Atmos. Chem. Phys., 12, 1179511817, https://doi.org/10.5194/acp-12-11795-2012, 2012.

Ehn, M., Kleist, E., Junninen, H., Petäjä, T., Lönn, G., Schobesberger, S., Dal Maso, M., Trimborn, A., Kulmala, M., Worsnop, D. R., Wahner, A., Wildt, J., and Mentel, Th. F.: Gas phase formation of extremely oxidized pinene reaction products in chamber and ambient air, Atmos. Chem. Phys., 12, 5113-5127, https://doi.org/10.5194/acp-12-5113-2012, 2012.

Ehn, M., Thornton, J. A., Kleist, E., Sipila, M., Junninen, H., Pullinen, I., Springer, M., Rubach, F., Tillmann, R., Lee, B., Lopez-Hilfiker, F., Andres, S., Acir, I.-H., Rissanen, M., Jokinen, T., Schobesberger, S., Kangasluoma, J., Kontkanen, J., Nieminen, T., Kurten, T., Nielsen, L. B., Jorgensen, S., Kjaergaard, H. G., Canagaratna, M., Dal Maso, M., Berndt, T., Petaja, T., Wahner, A., Kerminen, V.-M., Kulmala, M., Worsnop, D. R., Wildt, J., and Mentel, T. F.: A large source of lowvolatility secondary organic aerosol, Nature, 506, 476-479, https://doi.org/10.1038/nature13032, 2014.

Fry, J. L., Draper, D. C., Barsanti, K. C., Smith, J. N., Ortega, J., Winkler, P. M., Lawler, M. J., Brown, S. S., Edwards, P. M., Cohen, R. C., and Lee, L.: Secondary Organic Aerosol Formation and Organic Nitrate Yield from $\mathrm{NO}_{3}$ Oxidation of Biogenic Hydrocarbons, Environ. Sci. Technol., 48, 11944-11953, https://doi.org/10.1021/es502204x, 2014.

Guenther, A., Hewitt, C. N., Erickson, D., Fall, R., Geron, C., Graedel, T., Harley, P., Klinger, L., Lerdau, M., McKay, W. A., Pierce, T., Scholes, B., Steinbrecher, R., Tallamraju, R., Taylor, J., and Zimmerman, P.: A Global-model of natural volatile organic-compound emissions, J. Geophys. Res.-Atmos., 100, 8873-8892, https://doi.org/10.1029/94jd02950, 1995.

Hakola, H., Tarvainen, V., Bäck, J., Ranta, H., Bonn, B., Rinne, J., and Kulmala, M.: Seasonal variation of mono- and sesquiterpene emission rates of Scots pine, Biogeosciences, 3, 93-101, https://doi.org/10.5194/bg-3-93-2006, 2006.

Hakola, H., Hellén, H., Hemmilä, M., Rinne, J., and Kulmala, M.: In situ measurements of volatile organic compounds in a boreal forest, Atmos. Chem. Phys., 12, 11665-11678, https://doi.org/10.5194/acp-12-11665-2012, 2012.

Hari, P. and Kulmala, M.: Station for Measuring EcosystemAtmosphere Relations (SMEAR II), Boreal Environ. Res., 10, 315-322, 2005.

Huang, S., Rahn, K. A., and Arimoto, R.: Testing and optimizing two factor-analysis techniques on aerosol at Narragansett, Rhode Island, Atmos. Environ., 33, 2169-2185, https://doi.org/10.1016/S1352-2310(98)00324-0, 1999.
Jokinen, T., Sipilä, M., Junninen, H., Ehn, M., Lönn, G., Hakala, J., Petäjä, T., Mauldin III, R. L., Kulmala, M., and Worsnop, D. R.: Atmospheric sulphuric acid and neutral cluster measurements using CI-APi-TOF, Atmos. Chem. Phys., 12, 4117-4125, https://doi.org/10.5194/acp-12-4117-2012, 2012.

Kirkby, J., Duplissy, J., Sengupta, K., Frege, C., Gordon, H., Williamson, C., Heinritzi, M., Simon, M., Yan, C., Almeida, J., Troestl, J., Nieminen, T., Ortega, I. K., Wagner, R., Adamov, A., Amorim, A., Bernhammer, A.-K., Bianchi, F., Breitenlechner, M., Brilke, S., Chen, X., Craven, J., Dias, A., Ehrhart, S., Flagan, R. C., Franchin, A., Fuchs, C., Guida, R., Hakala, J., Hoyle, C. R., Jokinen, T., Junninen, H., Kangasluoma, J., Kim, J., Krapf, M., Kuerten, A., Laaksonen, A., Lehtipalo, K., Makhmutov, V., Mathot, S., Molteni, U., Onnela, A., Peraekylae, O., Piel, F., Petaejae, T., Praplan, A. P., Pringle, K., Rap, A., Richards, N. A. D., Riipinen, I., Rissanen, M. P., Rondo, L., Sarnela, N., Schobesberger, S., Scott, C. E., Seinfeld, J. H., Sipilae, M., Steiner, G., Stozhkov, Y., Stratmann, F., Tome, A., Virtanen, A., Vogel, A. L., Wagner, A. C., Wagner, P. E., Weingartner, E., Wimmer, D., Winkler, P. M., Ye, P., Zhang, X., Hansel, A., Dommen, J., Donahue, N. M., Worsnop, D. R., Baltensperger, U., Kulmala, M., Carslaw, K. S., and Curtius, J.: Ion-induced nucleation of pure biogenic particles, Nature, 533, 521-526, https://doi.org/10.1038/nature17953, 2016.

Kulmala, M., Kontkanen, J., Junninen, H., Lehtipalo, K., Manninen, H. E., Nieminen, T., Petäjä, T., Sipilä, M., Schobesberger, S., Rantala, P., Franchin, A., Jokinen, T., J?rvinen, E., Aijälä, M., Kangasluoma, J., Hakala, J., Aalto, P. P., Paasonen, P., Mikkilä, J., Vanhanen, J., Aalto, J., Hakola, H., Makkonen, U., Ruuskanen, T., Mauldin, R. L., Duplissy, J., Vehkamäki, H., Bäck, J., Kortelainen, A., Riipinen, I., Kurtén, T., Johnston, M. V., Smith, J. N., Ehn, M., Mentel, T. F., Lehtinen, K. E. J., Laaksonen, A., Kerminen, V.-M., and Worsnop, D. R.: Direct Observations of Atmospheric Aerosol Nucleation, Science, 339, 943 946, https://doi.org/10.1126/science.1227385, 2013.

Lamarque, J.-F., Bond, T. C., Eyring, V., Granier, C., Heil, A., Klimont, Z., Lee, D., Liousse, C., Mieville, A., Owen, B., Schultz, M. G., Shindell, D., Smith, S. J., Stehfest, E., Van Aardenne, J., Cooper, O. R., Kainuma, M., Mahowald, N., McConnell, J. R., Naik, V., Riahi, K., and van Vuuren, D. P.: Historical (1850-2000) gridded anthropogenic and biomass burning emissions of reactive gases and aerosols: methodology and application, Atmos. Chem. Phys., 10, 7017-7039, https://doi.org/10.5194/acp-10-7017-2010, 2010.

Lee, B. H., Lopez-Hilfiker, F. D., Mohr, C., Kurtén, T., Worsnop, D. R., and Thornton, J. A.: An Iodide-Adduct HighResolution Time-of-Flight Chemical-Ionization Mass Spectrometer: Application to Atmospheric Inorganic and Organic Compounds, Environ. Sci. Technol., 48, 6309-6317, https://doi.org/10.1021/es500362a, 2014.

Lehtipalo, K., Yan, C., Dada, L., Bianchi, F., Xiao, M., Wagner, R., Stolzenburg, D., Ahonen, L. R., Amorim, A., Baccarini, A., Bauer, P. S., Baumgartner, B., Bergen, A., Bernhammer, A.-K., Breitenlechner, M., Brilke, S., Buchholz, A., Mazon, S. B., Chen, D., Chen, X., Dias, A., Dommen, J., Draper, D. C., Duplissy, J., Ehn, M., Finkenzeller, H., Fischer, L., Frege, C., Fuchs, C., Garmash, O., Gordon, H., Hakala, J., He, X., Heikkinen, L., Heinritzi, M., Helm, J. C., Hofbauer, V., Hoyle, C. R., Jokinen, T., Kangasluoma, J., Kerminen, V.-M., Kim, C., Kirkby, J., Kontka- 
nen, J., Kürten, A., Lawler, M. J., Mai, H., Mathot, S., Mauldin, R. L., Molteni, U., Nichman, L., Nie, W., Nieminen, T., Ojdanic, A., Onnela, A., Passananti, M., Petäjä, T., Piel, F., Pospisilova, V., Quéléver, L. L. J., Rissanen, M. P., Rose, C., Sarnela, N., Schallhart, S., Schuchmann, S., Sengupta, K., Simon, M., Sipilä, M., Tauber, C., Tomé, A., Tröstl, J., Väisänen, O., Vogel, A. L., Volkamer, R., Wagner, A. C., Wang, M., Weitz, L., Wimmer, D., Ye, P., Ylisirniö, A., Zha, Q., Carslaw, K. S., Curtius, J., Donahue, N. M., Flagan, R. C., Hansel, A., Riipinen, I., Virtanen, A., Winkler, P. M., Baltensperger, U., Kulmala, M., and Worsnop, D. R.: Multicomponent new particle formation from sulfuric acid, ammonia, and biogenic vapors, J. Sci. Adv., 4, eaau5363, https://doi.org/10.1126/sciadv.aau5363, 2018.

Liebmann, J., Karu, E., Sobanski, N., Schuladen, J., Ehn, M., Schallhart, S., Quéléver, L., Hellen, H., Hakola, H., Hoffmann, T., Williams, J., Fischer, H., Lelieveld, J., and Crowley, J. N.: Direct measurement of $\mathrm{NO}_{3}$ radical reactivity in a boreal forest, Atmos. Chem. Phys., 18, 3799-3815, https://doi.org/10.5194/acp18-3799-2018, 2018.

Mohr, C., Lopez-Hilfiker, F. D., Yli-Juuti, T., Heitto, A., Lutz, A., Hallquist, M., D’Ambro, E. L., Rissanen, M. P., Hao, L., Schobesberger, S., Kulmala, M., Mauldin III, R. L., Makkonen, U., Sipilä, M., Petäjä, T., and Thornton, J. A.: Ambient observations of dimers from terpene oxidation in the gas phase: Implications for new particle formation and growth, Geophys. Res. Lett., 44, 2958-2966, https://doi.org/10.1002/2017gl072718, 2017.

Nah, T., Sanchez, J., Boyd, C. M., and Ng, N. L.: Photochemical Aging of $\alpha$-pinene and $\beta$-pinene Secondary Organic Aerosol formed from Nitrate Radical Oxidation, Environ. Sci. Technol., 50, 222-231, https://doi.org/10.1021/acs.est.5b04594, 2016.

Ng, N. L., Brown, S. S., Archibald, A. T., Atlas, E., Cohen, R. C., Crowley, J. N., Day, D. A., Donahue, N. M., Fry, J. L., Fuchs, H., Griffin, R. J., Guzman, M. I., Herrmann, H., Hodzic, A., Iinuma, Y., Jimenez, J. L., Kiendler-Scharr, A., Lee, B. H., Luecken, D. J., Mao, J., McLaren, R., Mutzel, A., Osthoff, H. D., Ouyang, B., Picquet-Varrault, B., Platt, U., Pye, H. O. T., Rudich, Y., Schwantes, R. H., Shiraiwa, M., Stutz, J., Thornton, J. A., Tilgner, A., Williams, B. J., and Zaveri, R. A.: Nitrate radicals and biogenic volatile organic compounds: oxidation, mechanisms, and organic aerosol, Atmos. Chem. Phys., 17, 2103-2162, https://doi.org/10.5194/acp-17-2103-2017, 2017.

Orlando, J. J. and Tyndall, G. S.: Laboratory studies of organic peroxy radical chemistry: an overview with emphasis on recent issues of atmospheric significance, J. Chem. Soc. Rev., 41, 62946317, 2012.

Paatero, P. and Tapper, U.: Positive matrix factorization: A nonnegative factor model with optimal utilization of error estimates of data values, Environmetrics, 5, 111-126, 1994.

Paatero, P.: Least squares formulation of robust non-negative factor analysis, Chemometr. Intell. Lab., 37, 23-35, https://doi.org/10.1016/S0169-7439(96)00044-5, 1997.

Paatero, P.: The Multilinear Engine-A Table-Driven, Least Squares Program for Solving Multilinear Problems, Including the n-Way Parallel Factor Analysis Model, J. Comput. Graph. Stat., 8, 854888, https://doi.org/10.1080/10618600.1999.10474853, 1999.

Paulson, S. E. and Orlando, J. J.: The reactions of ozone with alkenes: An important source of $\mathrm{HO}_{\mathrm{x}}$ in the boundary layer, Geophys. Res. Lett., 23, 3727-3730, https://doi.org/10.1029/96g103477, 1996.
Peräkylä, O., Riva, M., Heikkinen, L., Quéléver, L., Roldin, P., and Ehn, M.: Experimental investigation into the volatilities of highly oxygenated organic molecules (HOMs), Atmos. Chem. Phys., 20, 649-669, https://doi.org/10.5194/acp-20-649-2020, 2020.

Perraud, V., Bruns, E. A., Ezell, M. J., Johnson, S. N., Greaves, J., and Finlayson-Pitts, B. J.: Identification of Organic Nitrates in the $\mathrm{NO}_{3}$ Radical Initiated Oxidation of $\alpha$-Pinene by Atmospheric Pressure Chemical Ionization Mass Spectrometry, Environ. Sci. Technol., 44, 5887-5893, https://doi.org/10.1021/es1005658, 2010.

Polissar, A. V., Hopke, P. K., Paatero, P., Malm, W. C., and Sisler, J. F.: Atmospheric aerosol over Alaska: 2. Elemental composition and sources, J. Geophys. Res.-Atmos., 103, 19045-19057, 1998.

Pope III, C. A., Ezzati, M., and Dockery, D. W.: Fine-particulate air pollution and life expectancy in the United States, New Engl. J. Med., 360, 376-386, 2009.

Riva, M., Rantala, P., Krechmer, J. E., Peräkylä, O., Zhang, Y., Heikkinen, L., Garmash, O., Yan, C., Kulmala, M., Worsnop, D., and Ehn, M.: Evaluating the performance of five different chemical ionization techniques for detecting gaseous oxygenated organic species, Atmos. Meas. Tech., 12, 2403-2421, https://doi.org/10.5194/amt-12-2403-2019, 2019.

Shiraiwa, M., Ueda, K., Pozzer, A., Lammel, G., Kampf, C. J., Fushimi, A., Enami, S., Arangio, A. M., Fröhlich-Nowoisky, J., Fujitani, Y., Furuyama, A., Lakey, P. S. J., Lelieveld, J., Lucas, K., Morino, Y., Pöschl, U., Takahama, S., Takami, A., Tong, H., Weber, B., Yoshino, A., and Sato, K.: Aerosol Health Effects from Molecular to Global Scales, Environ. Sci. Technol., 51, 13545-13567, https://doi.org/10.1021/acs.est.7b04417, 2017.

Song, Y., Shao, M., Liu, Y., Lu, S., Kuster, W., Goldan, P., and Xie, S.: Source apportionment of ambient volatile organic compounds in Beijing, Environ. Sci. Technol., 41, 4348-4353, 2007.

Spittler, M., Barnes, I., Bejan, I., Brockmann, K. J., Benter, T., and Wirtz, K.: Reactions of $\mathrm{NO}_{3}$ radicals with limonene and $\alpha$ pinene: Product and SOA formation, Atmos. Environ., 40, 116127, https://doi.org/10.1016/j.atmosenv.2005.09.093, 2006.

Stocker, T., Qin, D., Plattner, G., Tignor, M., Allen, S., Boschung, J., Nauels, A., Xia, Y., Bex, V., and Midgley, P.: IPCC, 2013: Climate Change 2013: The Physical Science Basis. Contribution of Working Group I to the Fifth Assessment Report of the Intergovernmental Panel on Climate Change, 1535 pp., Cambridge Univ. Press, Cambridge, UK, and New York, 2013.

Troestl, J., Chuang, W. K., Gordon, H., Heinritzi, M., Yan, C., Molteni, U., Ahlm, L., Frege, C., Bianchi, F., Wagner, R., Simon, M., Lehtipalo, K., Williamson, C., Craven, J. S., Duplissy, J., Adamov, A., Almeida, J., Bernhammer, A.-K., Breitenlechner, M., Brilke, S., Dias, A., Ehrhart, S., Flagan, R. C., Franchin, A., Fuchs, C., Guida, R., Gysel, M., Hansel, A., Hoyle, C. R., Jokinen, T., Junninen, H., Kangasluoma, J., Keskinen, H., Kim, J., Krapf, M., Kuerten, A., Laaksonen, A., Lawler, M., Leiminger, M., Mathot, S., Moehler, O., Nieminen, T., Onnela, A., Petaejae, T., Piel, F. M., Miettinen, P., Rissanen, M. P., Rondo, L., Sarnela, N., Schobesberger, S., Sengupta, K., Sipila, M., Smith, J. N., Steiner, G., Tome, A., Virtanen, A., Wagner, A. C., Weingartner, E., Wimmer, D., Winkler, P. M., Ye, P., Carslaw, K. S., Curtius, J., Dommen, J., Kirkby, J., Kulmala, M., Riipinen, I., Worsnop, D. R., Donahue, N. M., and Baltensperger, U.: The role of low-volatility organic compounds in 
initial particle growth in the atmosphere, Nature, 533, 527-531, https://doi.org/10.1038/nature18271, 2016.

Ulbrich, I. M., Canagaratna, M. R., Zhang, Q., Worsnop, D. R., and Jimenez, J. L.: Interpretation of organic components from Positive Matrix Factorization of aerosol mass spectrometric data, Atmos. Chem. Phys., 9, 2891-2918, https://doi.org/10.5194/acp-92891-2009, 2009.

Visser, S., Slowik, J. G., Furger, M., Zotter, P., Bukowiecki, N., Canonaco, F., Flechsig, U., Appel, K., Green, D. C., Tremper, A. H., Young, D. E., Williams, P. I., Allan, J. D., Coe, H., Williams, L. R., Mohr, C., Xu, L., Ng, N. L., Nemitz, E., Barlow, J. F., Halios, C. H., Fleming, Z. L., Baltensperger, U., and Prévôt, A. S. H.: Advanced source apportionment of size-resolved trace elements at multiple sites in London during winter, Atmos. Chem. Phys., 15, 11291-11309, https://doi.org/10.5194/acp-15-112912015, 2015.

Yan, C., Nie, W., Äijälä, M., Rissanen, M. P., Canagaratna, M. R., Massoli, P., Junninen, H., Jokinen, T., Sarnela, N., Häme, S. A. K., Schobesberger, S., Canonaco, F., Yao, L., Prévôt, A. S. H., Petäjä, T., Kulmala, M., Sipilä, M., Worsnop, D. R., and Ehn, M.: Source characterization of highly oxidized multifunctional compounds in a boreal forest environment using positive matrix factorization, Atmos. Chem. Phys., 16, 12715-12731, https://doi.org/10.5194/acp-16-12715-2016, 2016.
Zha, Q., Yan, C., Junninen, H., Riva, M., Sarnela, N., Aalto, J., Quéléver, L., Schallhart, S., Dada, L., Heikkinen, L., Peräkylä, O., Zou, J., Rose, C., Wang, Y., Mammarella, I., Katul, G., Vesala, T., Worsnop, D. R., Kulmala, M., Petäjä, T., Bianchi, F., and Ehn, M.: Vertical characterization of highly oxygenated molecules (HOMs) below and above a boreal forest canopy, Atmos. Chem. Phys., 18, 17437-17450, https://doi.org/10.5194/acp-18-17437-2018, 2018.

Zhang, Q., Jimenez, J. L., Canagaratna, M. R., Ulbrich, I. M., Ng, N. L., Worsnop, D. R., and Sun, Y.: Understanding atmospheric organic aerosols via factor analysis of aerosol mass spectrometry: a review, Anal. Bioanal. Chem., 401, 3045-3067, https://doi.org/10.1007/s00216-011-5355-y, 2011.

Zhang, Y., Lin, Y., Cai, J., Liu, Y., Hong, L., Qin, M., Zhao, Y., Ma, J., Wang, X., and Zhu, T.: Atmospheric PAHs in North China: spatial distribution and sources, Sci. Total Environ., 565, 994 1000, 2016.

Zhang, Y., Cai, J., Wang, S., He, K., and Zheng, M.: Review of receptor-based source apportionment research of fine particulate matter and its challenges in China, Sci. Total Environ., 586, $917-$ 929, 2017.

Zhang, Y., Peräkylä, O., Yan, C., Heikkinen, L., Äijälä, M., Daellenbach, K. R., Zha, Q., Riva, M., Garmash, O., Junninen, H., Paatero, P., Worsnop, D., and Ehn, M.: A novel approach for simple statistical analysis of high-resolution mass spectra, Atmos. Meas. Tech., 12, 3761-3776, https://doi.org/10.5194/amt12-3761-2019, 2019. 